\title{
The Influence of Thermal Cycles on the Microstructure of Grade 92 Steel
}

\begin{abstract}
X. XU, G.D. WEST, J.A. SIEFERT, J.D. PARKER, and R.C. THOMSON (1)
The microstructure in the heat-affected zone (HAZ) of welds made from the $9 \mathrm{wt}$ pct chromium martensitic Grade 92 steel is complex and has not yet been completely understood. There is a lack of systematic microstructural investigations to define the different regions of the microstructure across the HAZ of Grade 92 steel welds as a function of the welding process. In this study, the microstructure in the HAZ of an as-fabricated single-pass bead-on-plate weld on a parent metal of Grade 92 steel was systematically investigated by using an extensive range of electron and ion-microscopy-based techniques. A dilatometer was used to apply controlled thermal cycles to simulate the microstructures in the different regions of the HAZ. A wide range of microstructural properties in the simulated materials were then characterized and compared with the experimental observations from the weld HAZ. It was found that the microstructure in the HAZ of a single-pass Grade 92 steel weld can be categorized as a function of a decreasing peak temperature reached as (1) the completely transformed (CT) region, in which the original matrix is completely reaustenitized with complete dissolution of the pre-existing secondary precipitate particles; (2) the partially transformed (PT) region, where the original matrix is partially reaustenitized along with a partial dissolution of the secondary precipitate particles from the original matrix; and (3) the overtempered (OT) region, where the pre-existing precipitate particles coarsen. The PT region is considered to be the susceptible area for damage in the commonly reported HAZ failures in weldments constructed from these types of steels.
\end{abstract}

DOI: $10.1007 / \mathrm{s} 11661-017-4306-4$

(C) The Author(s) 2017. This article is an open access publication

\section{INTRODUCTION}

ENGINEERING steels that operate under high-temperature creep conditions typically contain alloying elements that, under controlled heat treatment conditions, lead to the formation of precipitates. During the development of new steels, heat treatment trials are carried out to define the temperature ranges for the normalizing and tempering processes, which will result in an appropriate type, size, and distribution of precipitates in order to optimize the mechanical properties. However, after the initial fabrication of the parent material, in most pressure boundary applications of these steels, fusion welding is also required. These fusion welding processes introduce thermal cycles in the base metal, with the region subject to these influences typically termed the "heat-affected zone" (HAZ). The specific thermal history of these processes modifies the

X. XU, G.D. WEST, and R.C. THOMSON are with the Department of Materials, Loughborough University, Loughborough, LE11 3TU, UK. Contact email: R.C.Thomson@lboro.ac.uk J.A. SIEFERT and J.D. PARKER are with EPRI, Charlotte, NC 28262.

Manuscript submitted October 28, 2016.

Article published online September 11, 2017 microstructure within the HAZ and, thus, results in a variation in the corresponding mechanical properties.

Experience has demonstrated that the modification of properties includes changes to creep strength, ductility and fracture resistance. In extreme cases, these changes in properties can lead to failure. For example, cracking in $0.5 \mathrm{Cr} 0.5 \mathrm{Mo} 0.25 \mathrm{~V}$ low alloy steel welds was found to occur during the postweld heat treatment and in the HAZ region adjacent to the fusion line. ${ }^{[1]}$ Research was carried out in order to determine specific thermal cycles and the resulting changes in the microstructure and properties of the HAZ and the magnitude and distribution of residual stresses in such low alloy steels. It was established that reheat cracking was the direct result of relaxation of residual stresses in microstructures with low creep ductility. The low ductility in the region immediately adjacent to the fusion line was a consequence of both the high-temperature cycles, which resulted in a large prior austenite grain size (PAGS) $(>100 \mu \mathrm{m})$, and compositions that had relatively high levels of carbon and vanadium, which increased the high-temperature strength.

One of the outcomes of this early research was that a generalized approach to describe HAZ microstructures was published for welds made from the low alloy ferritic and bainitic steels. ${ }^{[1,2]}$ These descriptions have continued 
to be used for steels that are within the family of 9 to 12 wt pct $\mathrm{Cr}$, tempered martensitic steels. The classical description for the HAZ that is commonly applied to most steel grades considers that it is divided into four regions ${ }^{[3]}$.

(1) the coarse-grained HAZ region, in which the original matrix was fully reaustenitized with a relatively large prior austenite grain (PAG) size and complete dissolution of the pre-existing secondary precipitate particles with a peak temperature significantly higher than the $A c_{3}$ temperature;

(2) the fine-grained HAZ region, in which the PAG size is smaller due to the presence of undissolved secondary precipitate particles and a peak temperature that is close to the $A c_{3}$ temperature;

(3) the intercritical HAZ region, in which the original matrix is partially reaustenitized with a peak temperature between the $A c_{1}$ and $A c_{3}$ temperatures; and

(4) the subcritical HAZ region, where the secondary precipitate particles are coarsened with a peak temperature below the $A c_{1}$ temperature.

Grade 92 steel is extensively applied in the power generation industry for components such as steam pipes, headers, and tubes. It is a tempered martensitic steel with a nominal chemical composition of 9Cr-0.5Mo-1.8WVNb (wt pct), which is typically heat treated by normalization at $1313 \mathrm{~K}$ to $1353 \mathrm{~K}\left(1040{ }^{\circ} \mathrm{C}\right.$ to $1080{ }^{\circ} \mathrm{C}$ ) followed by tempering at $1023 \mathrm{~K}$ to $1053 \mathrm{~K}$ $\left(750{ }^{\circ} \mathrm{C} \text { to } 780{ }^{\circ} \mathrm{C}\right)^{[4]}$ to achieve a tempered martensitic microstructure in combination with the secondary precipitates such as the grain boundary $\mathrm{M}_{23} \mathrm{C}_{6}$ carbides and the MX carbonitrides. ${ }^{[5]} \mathrm{A}$ variety of conventional arc welding techniques, such as gas tungsten arc welding (GTAW), shielded metal arc welding (SMAW), and submerged arc welding, ${ }^{[6]}$ are routinely applied in the fabrication of Grade 92 steel components.

The earlier classifications developed for the HAZ microstructure in ferritic and bainitic steels are commonly used in studies describing 9 to $12 \mathrm{wt}$ pct $\mathrm{Cr}$ steel weldments. ${ }^{[7-9]}$ However, it is apparent that there is no clear evidence for these steels that PAG size has a significant influence on properties, and indeed, where data are available, it appears that creep strength and ductility grain size are not a function of PAG size in tempered martensitic steels. One such example is the lack of evidence for a widespread susceptibility to reheat cracking as is documented for bainitic CrMoV steels.

Proper classification of the HAZ in martensitic, 9 to 12 wt pct $\mathrm{Cr}$ steels is motivated by the fact that these materials are typically life limited in service and under creep conditions by failures in the HAZ. This mechanism is commonly referred to as "Type IV cracking," terminology borrowed from failures in bainitic, $\mathrm{CrMoV}$ steels. HAZ failures in 9 to $12 \mathrm{wt}$ pct $\mathrm{Cr}$ steels are commonly reported as located in the outer edge of the "visible" HAZ close to the parent material. In this context, visible defines what can be observed using widely applied light microscopy techniques. It was reported that HAZ failures in 9 to $12 \mathrm{wt}$ pct $\mathrm{Cr}$ steel welds can be present either in the fine-grain or intercritical region, ${ }^{7]}$ accompanied by a significantly shortened lifetime of weldments compared to bulk material samples. ${ }^{[10]}$ A variety of microstructural factors, such as an inhomogeneous distribution of secondary precipitate particles, ${ }^{[8]}$ the presence of an exceptionally fine-grain structure, ${ }^{[1]}$ and excessively grown precipitate particles $^{[12]}$ were considered as the possible causes for Type IV failure. However, there is not yet consensus on whether a specific microstructural factor or a set of factors are dominant in causing HAZ failures. Since many components constructed from this family of steels exceed 100,000 hours in operation, there is a need to properly characterize HAZ regions and more clearly determine the factors contributing to the exact cause of $\mathrm{HAZ}$ failure in these materials.

Typical definitions of the HAZ microstructure in $9 \mathrm{wt}$ pct $\mathrm{Cr}$ steel welds are based on experimental observations from simple, conventional metallographic examination methods using light optical microscopes (LOMs), hardness testing, and, in some cases, basic evaluation in a scanning electron microscope. ${ }^{[13,14]}$ However, these techniques are limited in their ability to unambiguously identify critical microstructural parameters in each of the HAZ regions, such as the intrinsic grain structure properties and the spatial distribution and size of second-phase particles. It is, therefore, considered that in material systems with complex microstructures, such as those present in martensitic 9 to 12 wt pct $\mathrm{Cr}$ steels, the use of more advanced electron and ion-microscopy-based techniques, such as electron backscatter diffraction (EBSD) ${ }^{[15]}$ and ion-beam-induced secondary electron imaging, ${ }^{[16]}$ is essential to describe the microstructures accurately. Successful applications of these advanced characterization techniques on the microstructural characterization of the weld HAZ and the bulk materials of 9 wt pct $\mathrm{Cr}$ steels were reported in recent years. ${ }^{[8,17,18]}$ However, there is still a lack of systematic investigations in which the microstructural gradient across the HAZ of 9 wt pet $\mathrm{Cr}$ steel welds was thoroughly evaluated and directly linked to the local thermal gradient during welding.

In addition to studies in the HAZs of real welds, studies concerning simulated HAZ have also been reported in the literature. ${ }^{[7,19]}$ These materials are typically produced by exposing the raw parent metal materials to controlled heat cycles that simulate weld thermal cycles using a Gleeble simulator or a dilatometer. ${ }^{\left[{ }^{20]}\right.}$ In these works, comparisons of creep behavior were made between the HAZ simulation materials that were exposed to heat cycles with various peak temperatures under a range of creep testing conditions. A shorter creep rupture life and higher creep strain were identified in material that was exposed to the thermal cycles with a peak temperature close to the $A c_{3}$ temperature. ${ }^{[19]}$ Microstructural characterization was also conducted on HAZ simulation materials in more recent work (e.g., References 8 and 20). Evidence showing an inhomogeneous distribution of precipitate particles due to microsegregation was indicated after 
weld thermal cycle simulations with a peak temperature between the $A c_{1}$ and $A c_{3}$ temperatures. ${ }^{[8]}$ However, there still remains a lack of systematic studies in which the observed microstructure in the HAZ of actual welded samples can be linked with corresponded simulated HAZ in order to understand the exact relationship between the microstructural gradient in the HAZ and local thermal histories experienced.

This article describes research that was carried out to systematically investigate the microstructural development across the HAZ of Grade 92 welds, which is linked with microstructural observations in HAZ simulation materials in order to understand the microstructural gradient in the HAZ as a result of the thermal cycle introduced by weld manufacture. The characterization techniques employed include the more traditional approaches of optical metallography and hardness testing combined with the application of advanced analytical electron and ion-based microscopy techniques.

\section{EXPERIMENTAL METHODS}

\section{A. Thermal Cycles}

Representative heat flows for the thermal cycles in practical weld HAZs were predicted based on a heat conduction flow equation using the Smartweld software version 3. ${ }^{[21]}$ A moving round-shaped heat source on a semi-infinite body of material with a thickness of $10 \mathrm{~mm}$ was assumed. The calculations of heat flows by the Smartweld software were performed by using parameter sets that were appropriate for practical welding procedures including input power, electrode travel speed, and preheat temperature. In this case, the calculations were carried out under a condition that is similar to standard industrial welding procedures for the fabrication of shielded metal arc welds on a parent metal of Grade 92 steel. Details of the parameter sets used for the heat flow calculations are shown in Table I. The physical property sets of the parent metal for heat conduction modeling used a set of data that were obtained for $15-5 \mathrm{PH}$ stainless steel, which is a martensitic precipitation-strengthening stainless steel possessing similar physical properties to Grade 92 steel. Figure 1 shows the graphs detailing the weld thermal cycles as predicted by the Smartweld software.

Dilatometry heat cycles were then performed using a Bahr 805 dilatometer on samples that were obtained from a thick-section Grade 92 steam pipe that was normalized and tempered under a standard condition for industrial applications. Dilatometry heat cycles were designed based on the predicted thermal cycles by using heat conduction modeling, with the achievable ranges for heating and cooling conditions using the dilatometer system being taken into account. Therefore, a heating rate of $60 \mathrm{~K} / \mathrm{s}\left(60{ }^{\circ} \mathrm{C} / \mathrm{s}\right)$ and a cooling rate of $30 \mathrm{~K} / \mathrm{s}$ to $40 \mathrm{~K} / \mathrm{s}\left(30^{\circ} \mathrm{C} / \mathrm{s}\right.$ to $\left.40^{\circ} \mathrm{C} / \mathrm{s}\right)$ were used for the dilatometry heat cycles.

The $A c_{1}$ and $A c_{3}$ temperatures of the parent metal were then measured from the dimensional response as a function of temperature from the samples that were exposed to heating cycles with specific heating and cooling rates. An example of a typical dimensional response to temperature curve is shown in Figure 2(a). The transformation temperatures were carefully determined from the corresponding points in the curves where they deviated from the linear relationship between dimensional change and temperature at the start and end of phase transformations, as shown in Figure 2(b). Average values and standard deviations of transformation temperatures were determined from three independent measurements.

The $A e_{1}$ and the $A e_{3}$ temperatures of the parent metal were also calculated for comparison at the thermodynamic equilibrium state using the Thermo-Calc software version 4.1, with the TCFE database version 7 .

The peak temperatures of the heat cycles chosen to simulate the weld thermal cycles in the HAZ were selected to be above the $A c_{3}$ temperature, between the $A c_{1}$ and the $A c_{3}$ temperatures, and below the $A c_{1}$ temperature. Therefore, several peak temperatures of the heat cycles were chosen at $1523 \mathrm{~K}, 1373 \mathrm{~K}, 1273 \mathrm{~K}$, $1173 \mathrm{~K}, 1123 \mathrm{~K}$, and $1103 \mathrm{~K} \quad\left(1250{ }^{\circ} \mathrm{C}, 1100{ }^{\circ} \mathrm{C}\right.$, $1000{ }^{\circ} \mathrm{C}, 900{ }^{\circ} \mathrm{C}, 850{ }^{\circ} \mathrm{C}$, and $830^{\circ} \mathrm{C}$ ). Figure 3 provides a graph showing the details of the heat cycles that were used in order to simulate the welding process.

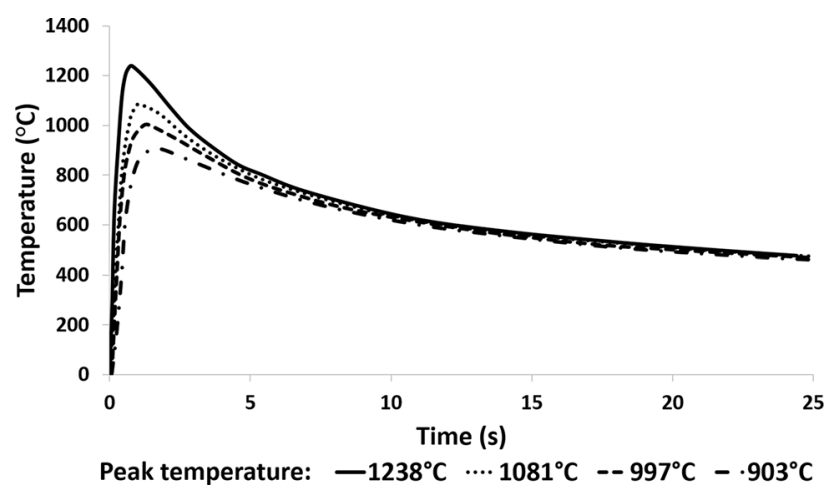

Fig. 1-Graph detailing the weld thermal cycles in the HAZ of a single-pass bead-on-plate Grade 92 weld, as predicted by the Smartweld software.

Table I. Parameter Sets Used for the Calculations Associated with the Prediction of Heat Flow Associated with the Weld Thermal Cycles Used

\begin{tabular}{lccc}
\hline Power $(\mathrm{W})$ & Travel Speed $(\mathrm{mm} / \mathrm{s})$ & Parent Metal Temperature $\left(\mathrm{K} /{ }^{\circ} \mathrm{C}\right)$ & Material Thickness $(\mathrm{mm})$ \\
\hline 2750 & 2.75 & $422 / 149$ & 10 \\
\hline
\end{tabular}




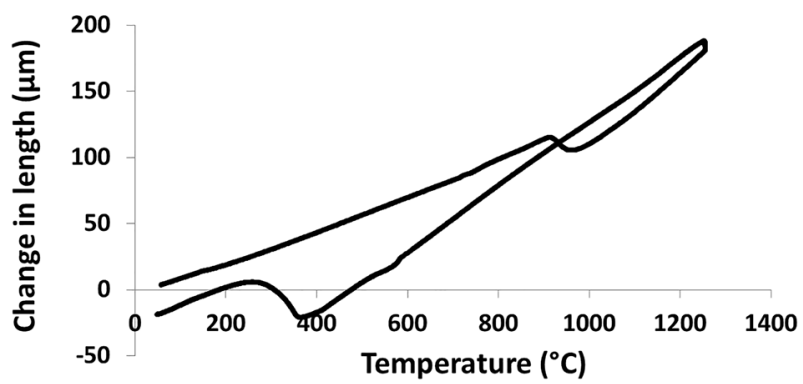

(a)

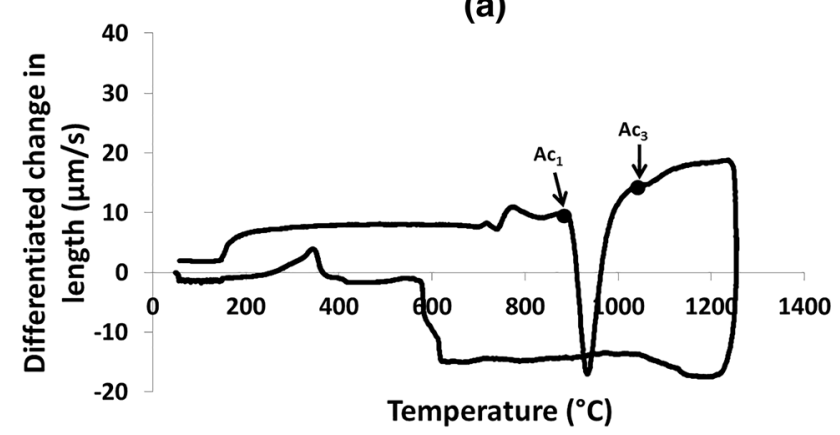

(b)

Fig. 2-Graphs showing (a) change-in-length vs temperature and (b) differentiated-change-in-length $v s$ temperature curves. The $A c_{1}$ and $A c_{3}$ temperatures were measured from the points where the dimensional change of samples deviated from a linear relationship with temperature.

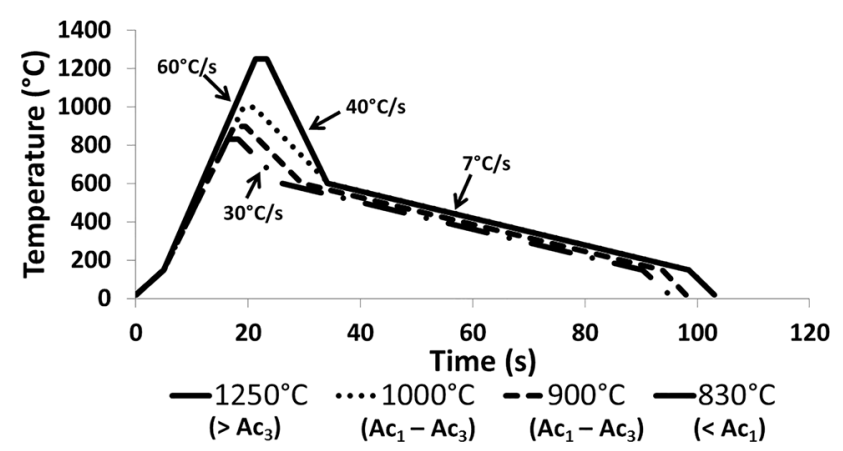

Fig. 3 - Graph showing the heat treatment cycles that were used for the simulations of weld thermal cycles.

\section{B. Materials and Welding Parameters}

A single-pass SMAW bead-on-plate weld was fabricated on a transverse section of a Grade 92 thick-section steam pipe using the identical experimental conditions as those used in the heat conduction calculations of heat cycles. The chemical composition of the parent metal in the SMAW weld was measured by using inductively coupled plasma-optical emission spectrometry (ICP-OE) and inductively coupled plasma-mass spectrometry (ICP-MS). Table II shows the measured chemical composition of the parent metal. The welding electrode that was used for the weld was a Midalloy Chromax E9015-B9 H4 coated electrode with a diameter of $3.2 \mathrm{~mm}$. The weld was produced using a current of $125 \mathrm{~A}$ and a voltage of $22 \mathrm{~V}$ with the electrode traveling at a speed of 165 to $175 \mathrm{~mm} \mathrm{~min}^{-1}$. The bead-on-plate weld was subsequently sectioned perpendicular to the welding direction to obtain the HAZ sample, as shown in Figure 4.

\section{Hardness Test and Microstructural Characterization}

The average hardness in the parent metal samples that were exposed to the simulated weld thermal cycles was measured using a Struers Durascan 70 hardness testing system with a Vickers indenter and an applied weight of $0.2 \mathrm{~kg}$. On each sample, 100 hardness indents were produced for sufficient statistical significance. Hardness mapping was also performed on the cross section of the SMAW bead-on-plate weld with the same instrument. Over 4500 hardness indents were automatically produced at an interval of $0.1 \mathrm{~mm}$ in the regions of the weld metal, the HAZ, and the parent metal over an area of $9.0 \times 5.5 \mathrm{~mm}^{2}$.

The samples were prepared for analysis using conventional metallographic preparation procedures. A final extended chemomechanical polishing step using a $0.02 \mu \mathrm{m}$ colloidal silica suspension was applied in order to eliminate the surface deformations that were introduced by the abrasive polishing stages.

An FEI Nova 600 Nanolab dual beam focused ion beam field emission gun was used to perform EBSD analyses of the matrix and ion-beam-induced secondary electron imaging of secondary precipitate particles. EBSD maps were collected using an EDAX Hikari camera at an accelerating voltage of $20 \mathrm{kV}$ and a nominal beam current of $24 \mathrm{nA}$. An overview of the matrix in the HAZ of the bead-on-plate weld was obtained by collecting low-magnification EBSD maps at a step size of $2 \mu \mathrm{m}$. The details of grain structure were provided by collecting EBSD maps at a higher magnification, with step sizes of 1 and $0.1 \mu \mathrm{m}$. Ion-beam-induced secondary electron micrographs were collected from the identical regions, where the EBSD maps were collected in the HAZ of the bead-on-plate weld and the parent metal samples that were exposed to the simulated weld thermal cycles. The ion beam was operated at an accelerating voltage of $30 \mathrm{kV}$ and a nominal beam current of $50 \mathrm{pA}$, with $\mathrm{XeF}_{2}$ gas flowing to enhance the contrast differential between the particles and the matrix. The number per unit area and the size of secondary precipitate particles in each of the regions of analysis in the weld HAZ were measured from three micrographs covering a total area of $410 \mu \mathrm{m}^{2}$ by using the ImageJ software version $1.47 \mathrm{t}$, whereas 10 micrographs covering a total area of $1375 \mu \mathrm{m}^{2}$ were collected from each of the simulated parent metal samples.

The secondary precipitate particles in the simulated parent metal samples that were exposed to weld thermal cycle simulations were extracted using carbon extraction replicas. The replicas were prepared from polished surfaces that were lightly etched by using Villela's reagent $(1 \mathrm{~g}$ picric acid, $5 \mathrm{~mL}$ hydrochloric acid, and $100 \mathrm{~mL}$ ethanol) for approximately 10 seconds. A thin film of carbon was then deposited onto the lightly etched surface using a Quorum Technologies Q150T ES coating system. The carbon film was electrolytically removed in a 10 pet hydrochloric acid in methanol solution. The 
Table II. Experimentally Measured Chemical Composition of the Grade 92 Parent Metal by Using ICP-OE and ICP-MS Methods

\begin{tabular}{|c|c|c|c|c|c|c|c|c|c|}
\hline \multicolumn{10}{|c|}{ Parent Metal (Weight Percent), Balance Fe } \\
\hline $\mathrm{Cr}$ & $\mathrm{Mn}$ & Mo & $\mathrm{Nb}$ & $\mathrm{Ni}$ & $\mathrm{Si}$ & $\mathrm{V}$ & $\mathrm{W}$ & $\mathrm{C}$ & B \\
\hline 8.797 & 0.49 & 0.43 & 0.062 & 0.38 & 0.211 & 0.188 & 1.836 & 0.113 & 0.0041 \\
\hline $\mathrm{N}$ & $\mathrm{Al}$ & $\mathrm{Cu}$ & $\mathrm{P}$ & $\mathrm{S}$ & $\mathrm{Ca}$ & $\mathrm{Co}$ & $\mathrm{Ti}$ & $\mathrm{Zr}$ & $\mathrm{Sn}$ \\
\hline 0.045 & 0.002 & 0.189 & 0.009 & 0.008 & 0.002 & 0.015 & 0.001 & 0.004 & 0.016 \\
\hline
\end{tabular}

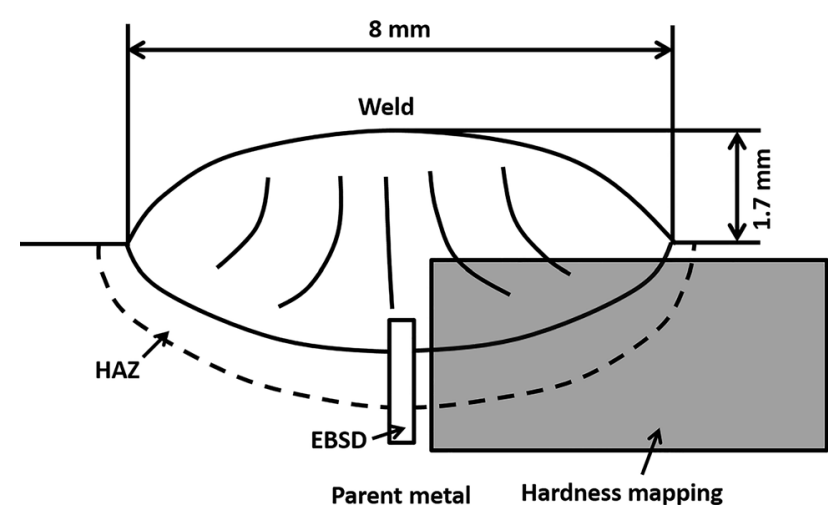

Fig. 4-Schematic diagram illustrating the cross section of a SMAW bead-on-plate Grade 92 weld. The white and gray boxes indicate the regions where the subsequent EBSD and hardness mapping analyses were performed, respectively.

replicas were collected on copper grids and then cleaned with methanol followed by deionized water. The precipitate particles on the carbon extraction replicas were first chemically analyzed by using energy-dispersive X-ray spectroscopy (EDX) in an FEI Tecnai F20 transmission electron microscope (TEM) equipped with an Oxford Instruments X-Max $80^{\mathrm{N}}$ TLE EDS system. The particles were also crystallographically identified either by the fast Fourier transformation (FFT) of the high-resolution (HR) TEM micrographs of the particles of interest or by using selected area electron diffraction (SAED) in a JEOL* JEM 2000FX TEM.

*JEOL is a trademark of Japan Electron Optics Ltd., Tokyo.

\section{RESULTS}

\section{A. Original Microstructure of the Parent Metal in the Grade 92 Bead-On-Plate Weld}

The transformation temperatures of the parent metal were measured for the simulated weld thermal cycle, as shown in Figure 3. The theoretical values of the transformation temperatures were also calculated at thermodynamic equilibrium. Table III shows a comparison between the experimentally measured values of the $A c_{1}$ and the $A c_{3}$ temperatures and the values obtained by thermodynamic calculations. The experimentally measured $A c_{1}$ and $A c_{3}$ temperatures of the parent metal are $82 \mathrm{~K}$ and $193 \mathrm{~K}\left(82^{\circ} \mathrm{C}\right.$ and $\left.193{ }^{\circ} \mathrm{C}\right)$ higher than the $A e_{1}$ and $A e_{3}$ temperatures, respectively.

The grain structure in the parent metal was characterized using EBSD mapping analysis. Figure 5 shows an EBSD grain orientation map providing an overview of microstructure and the overlaid images of the colored EBSD grain orientation and the EBSD grain boundary maps detailing the PAG and the martensitic substructure properties in the parent metal.

The parent metal exhibited a tempered martensitic microstructure composed of PAGs with a size of over $100 \mu \mathrm{m}$ (Figure 5(a)) and lathlike grains with a width of approximately $5 \mu \mathrm{m}$ within the PAG interiors (Figures 5(b) and (c)). In addition, it was observed in the parent metal sample that the misorientations of the boundaries within the martensitic substructure are predominantly in the range of 2 to 20 and 50 to $60 \mathrm{deg}$ (Figures 5(b) and (d)), whereas the boundary segments with a misorientation of 20 to $50 \mathrm{deg}$ predominantly belong to the PAGBs (Figures 5(c) and (d)). Although some segments with a misorientation of 20 to $50 \mathrm{deg}$ correspond to the precipitate particles that were not accurately indexed (Figure 5(d)), the fraction of these segments is much lower than the segments corresponding to PAGBs.

Similar observations on the martensitic steels were reported in the literature (e.g., Reference 22). The substructure boundaries that are within a misorientation of 2 to 20 and 50 to 60 deg were indicated as the boundaries between blocks and packets. ${ }^{[2]}$ Due to a Kurdjumov-Sachs orientation relationship between martensite and the parent austenite phases, the misorientations of the substructure boundaries, such as packet and block boundaries, are in the range of 2 to 20 and 50 to $60 \mathrm{deg} .{ }^{[22]}$ The misorientations of the PAGBs, however, are expected to follow a Mackenzie-type distribution of grain boundary misorientation for nontextured cubic structures, which shows a higher angular fraction in the misorientation range of 20 to $50 \mathrm{deg}$ than the other types of boundaries within the martensitic substructure. ${ }^{[23]}$ Therefore, classification of boundaries to different misorientation ranges (i.e., 2 to 20, 20 to 50, and 50 to $60 \mathrm{deg}$ ) can differentiate PAGBs and the other types of boundaries within the martensitic microstructure. Quantitative measurement of the lengths of the boundaries with misorientations in different ranges can, thus, indicate the properties of lath and grain structures, which was used throughout in order to understand the influence of weld thermal cycles on the lath and grain structure properties. 

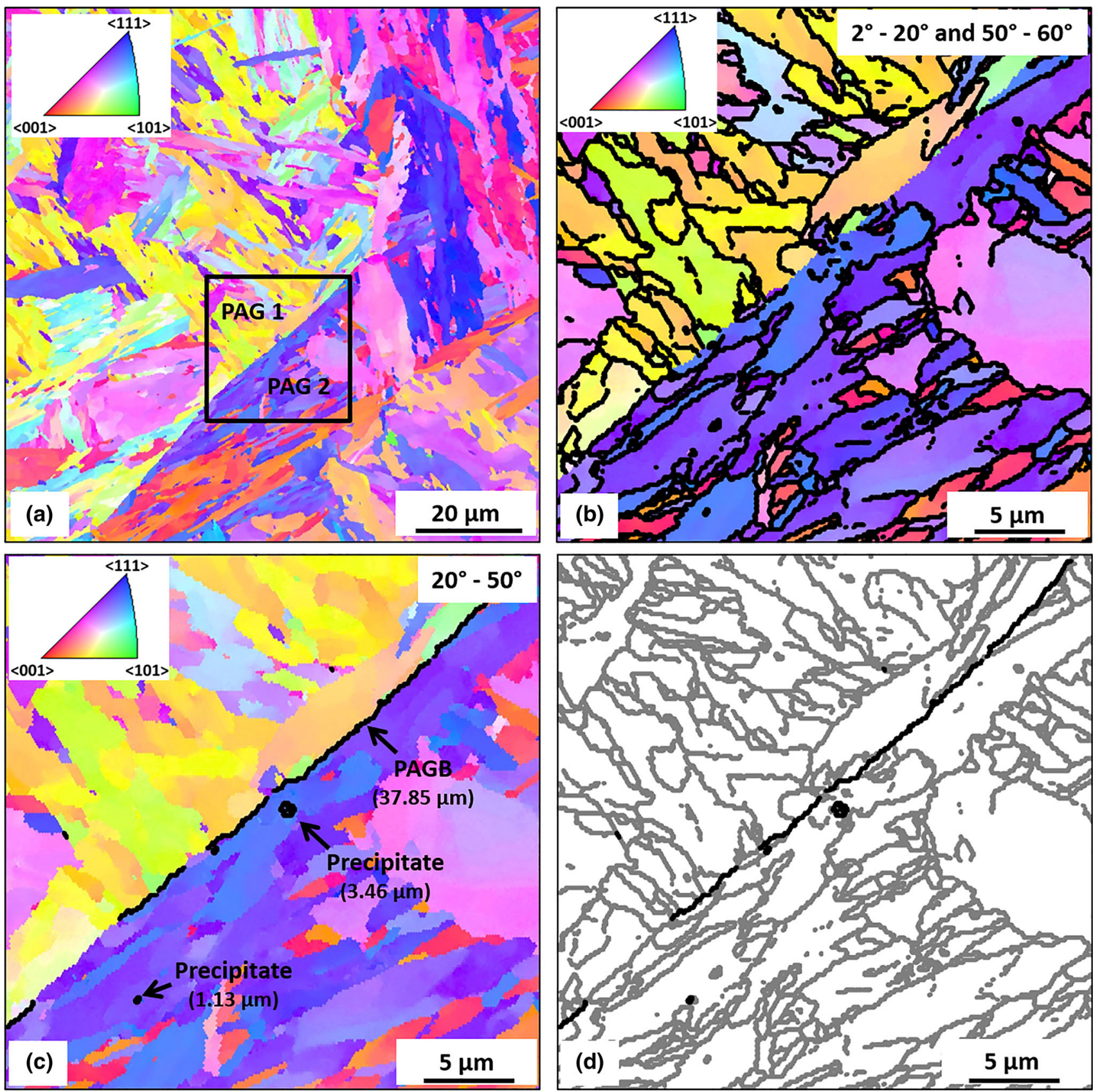

$2^{\circ}-20^{\circ}$ and $50^{\circ}-60^{\circ}$

$20^{\circ}-50^{\circ}$

Fig. 5- (a) EBSD grain orientation map providing an overview of the grain structure in the parent metal. The black box indicates the region where the EBSD maps, as shown in $(b)$ through $(d)$, were collected. (b) and (c) Overlaid images of the colored EBSD grain orientation and the EBSD grain boundary maps in which the outlines of (b) the 2 to 20 deg and the 50 to 60 deg and (c) the 20 to 50 deg boundaries are presented. (d) An EBSD grain boundary map in which the outlines of the 20 to 50 deg (black) and the 2 to 20 and 50 to 60 deg (gray) boundaries are both shown is also included.

EBSD grain boundary maps and ion-beam-induced secondary electron micrographs, as shown in Figure 6, were collected from identical regions in the parent metal to characterize the relationship between secondary precipitate particles and the surrounding grain and lath structures. Secondary precipitate particles were observed to be preferentially formed on both the lath and subgrain boundaries, with all boundary orientations decorated by secondary precipitate particles. 
Table III. Experimentally Measured Values of the $A c_{1}$ and the $A c_{3}$ Temperatures Using Dilatometry and the Values Obtained by Equilibrium Thermodynamic Calculations

\begin{tabular}{lccr}
\hline \multicolumn{2}{c}{ Dilatometry Measurements } & \multicolumn{2}{c}{ Thermodynamic Calculations } \\
\cline { 2 - 4 }$A c_{1}$ & $A c_{3}$ & $A e_{1}$ & $A e_{3}$ \\
\hline $1150 \pm 9 \mathrm{~K}$ & $1330 \pm 30 \mathrm{~K}$ & $1068 \mathrm{~K}$ & $1137 \mathrm{~K}$ \\
$877 \pm 9{ }^{\circ} \mathrm{C}$ & $1057 \pm 30^{\circ} \mathrm{C}$ & $795^{\circ} \mathrm{C}$ & $864^{\circ} \mathrm{C}$ \\
\hline
\end{tabular}
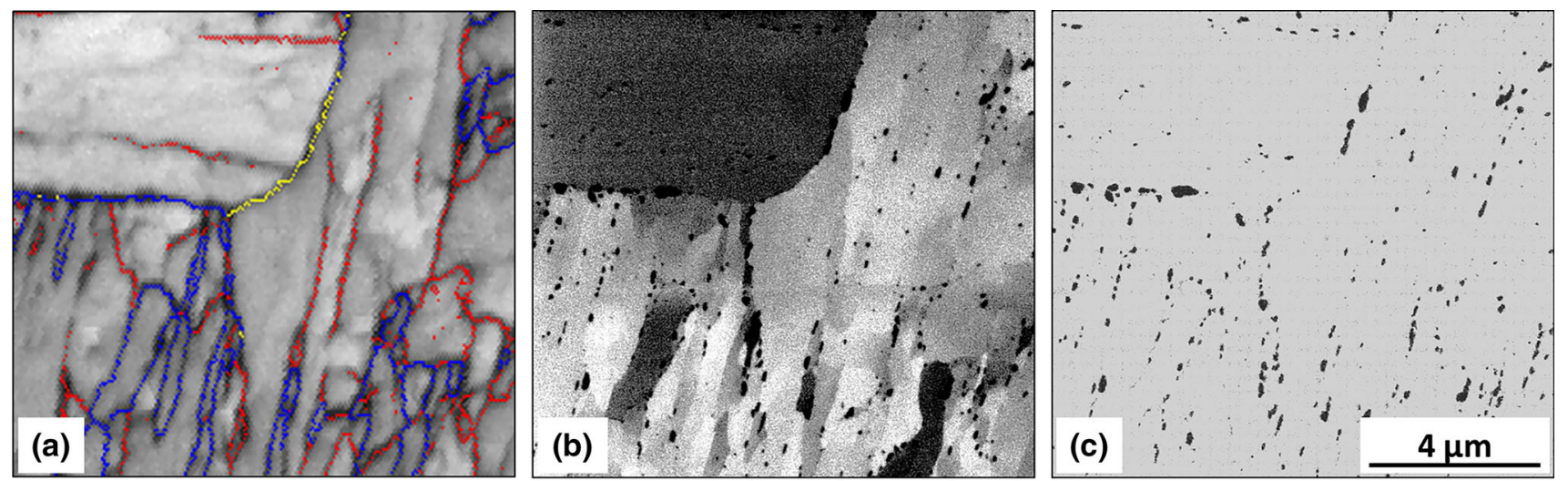

$-2^{\circ}-20^{\circ}-20^{\circ}-50^{\circ}-50^{\circ}-60^{\circ}$

Fig. 6- (a) EBSD grain boundary map and $(b)$ and $(c)$ ion-beam-induced secondary electron micrographs that were obtained from an identical region in the parent metal. The lath/grain boundaries in the map (a) are presented in different colors according to boundary misorientation.

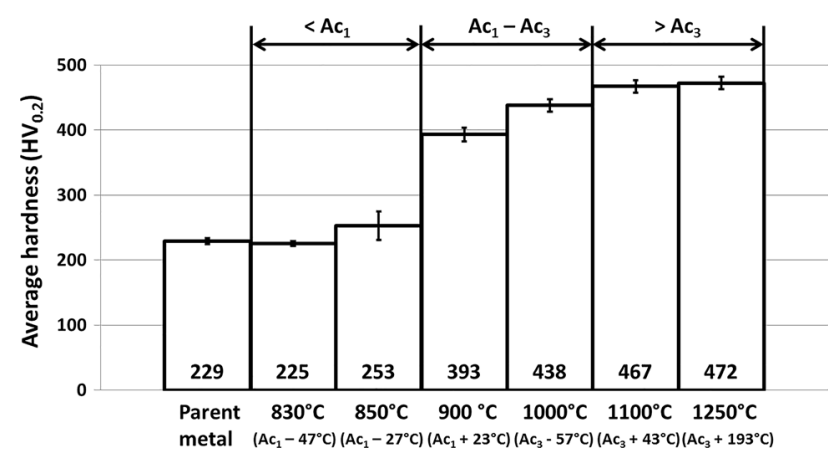

Fig. 7-Graph comparing the average hardness values of the Grade 92 parent metal samples after the simulated weld thermal cycles applied to the unexposed parent metal sample.

\section{B. Influences of Simulated Weld Thermal Cycles on Microstructure}

Figure 7 illustrates the hardness of the samples that underwent simulations of weld thermal cycles using the dilatometer. The hardness of the sample heated to a peak temperature of $1103 \mathrm{~K}\left(830^{\circ} \mathrm{C}\right)$ was similar to that of the original parent metal hardness (225 vs $229 \mathrm{HV}$, respectively). However, the hardness of the simulated samples with peak temperatures between $1123 \mathrm{~K}$ and $1273 \mathrm{~K}\left(850{ }^{\circ} \mathrm{C}\right.$ and $\left.1000{ }^{\circ} \mathrm{C}\right)$ significantly increased as the peak temperatures increased. A hardness of over 450 $\mathrm{HV}_{0.2}$ was obtained in the simulated sample with a peak temperature of $1523 \mathrm{~K}\left(1250{ }^{\circ} \mathrm{C}\right)$.

EBSD mapping analyses were performed on the samples that had received the simulated weld thermal cycles with a peak temperature between $1123 \mathrm{~K}$ and
$1523 \mathrm{~K}\left(850{ }^{\circ} \mathrm{C}\right.$ and $\left.1250{ }^{\circ} \mathrm{C}\right)$ in order to characterize the grain structure. Figure 8 shows the overlaid images of the colored EBSD grain orientation maps and the gray-scale EBSD image quality maps that were collected using a step size of $1 \mu \mathrm{m}$ and the EBSD grain boundary maps showing the 20 to $50 \mathrm{deg}$ PAGBs from an area of length $\sim 200 \mathrm{~m}$.

Figure 9 shows the obtained overlaid images of the colored EBSD grain orientation maps and the gray-scale EBSD image quality maps with a step size of $0.1 \mu \mathrm{m}$ (area of length $\sim 50 \mathrm{~m}$ ) from the simulated samples with a peak temperature between $1123 \mathrm{~K}$ and $1523 \mathrm{~K}$ $\left(850^{\circ} \mathrm{C}\right.$ and $\left.1250{ }^{\circ} \mathrm{C}\right)$ and the EBSD grain boundary maps showing the 2 to 20 and 50 to $60 \mathrm{deg}$ substructure boundaries in the same samples as those presented in Figure 8.

\section{Precipitation Behavior During the Simulated Weld Thermal Cycles}

The distribution of secondary precipitate particles in the simulated samples was characterized using ion-beam-induced secondary electron imaging after the weld thermal cycle simulations. Figure 10 shows the ion-beam-induced secondary electron micrographs that were obtained from the simulated samples with peak temperatures between $1103 \mathrm{~K}$ and $1373 \mathrm{~K}\left(830^{\circ} \mathrm{C}\right.$ and $1100^{\circ} \mathrm{C}$ ).

The distributions of secondary precipitate particles were quantitatively measured from ion-beam-induced secondary electron micrographs from the simulated 

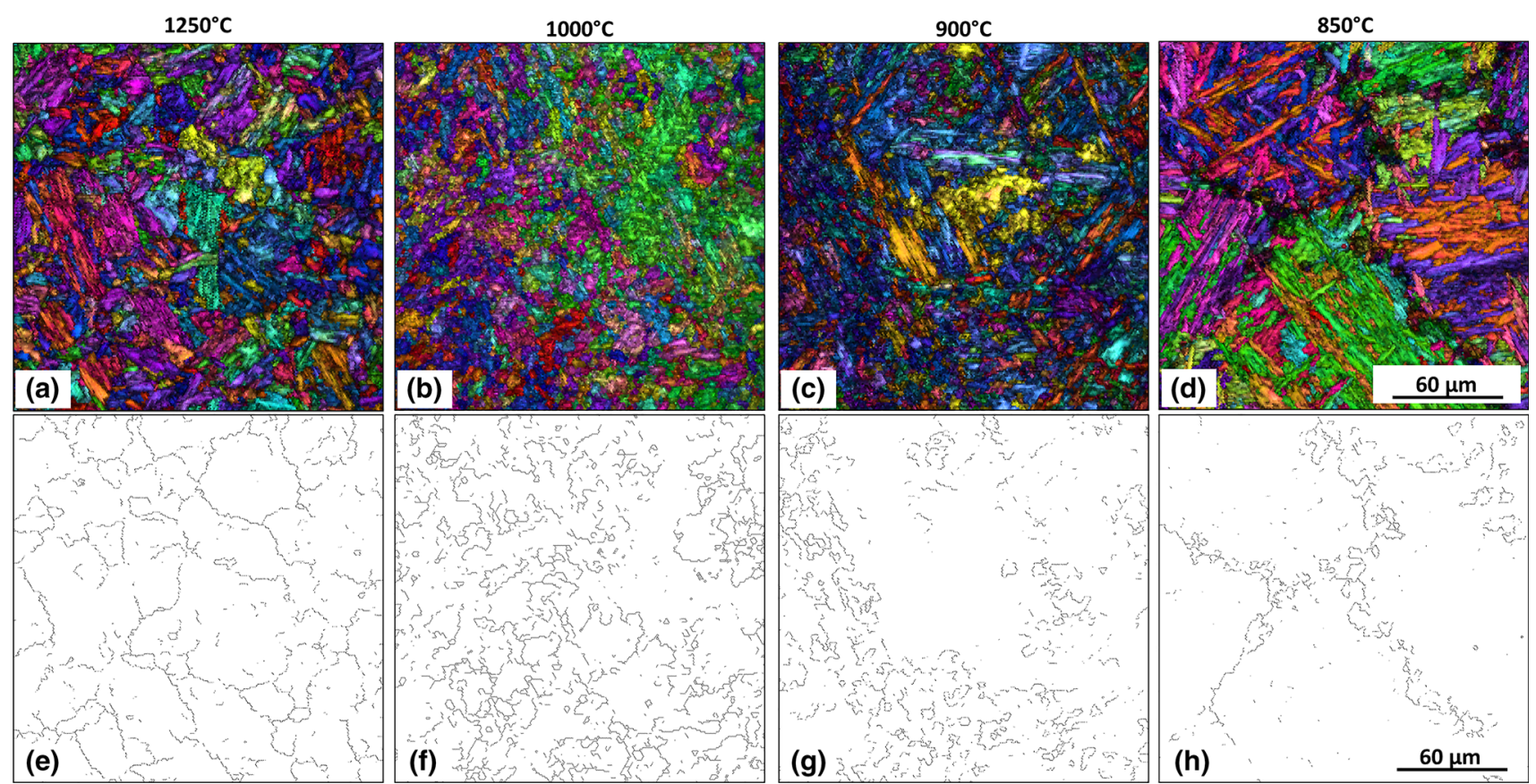

Fig. 8- (a) through $(d)$ Overlaid images of the colored EBSD grain orientation maps and the gray-scale EBSD image quality maps that were collected after weld thermal cycle simulations with a peak temperature of (a) $1523 \mathrm{~K}\left(1250{ }^{\circ} \mathrm{C}\right)$, (b) $1273 \mathrm{~K}\left(1000{ }^{\circ} \mathrm{C}\right),(c) 1173 \mathrm{~K}\left(900{ }^{\circ} \mathrm{C}\right)$, and (d) $1123 \mathrm{~K}\left(850^{\circ} \mathrm{C}\right)$. (e) through $(h)$ EBSD grain boundary maps are also presented to provide the details of the 20 to 50 deg PAGBs.
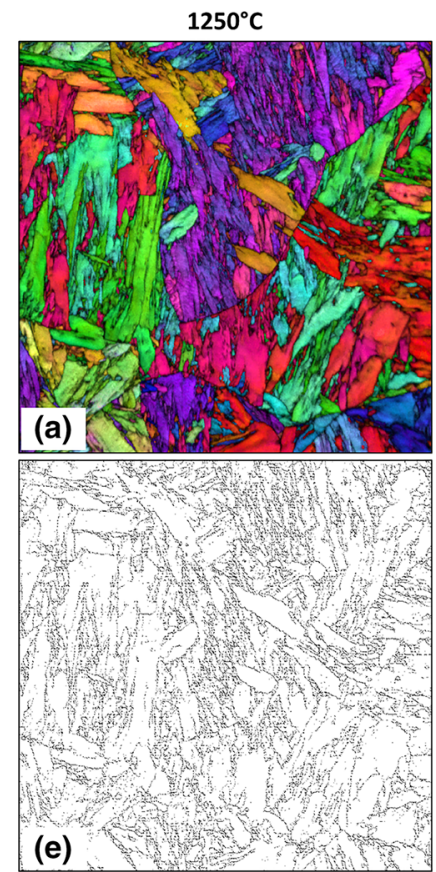
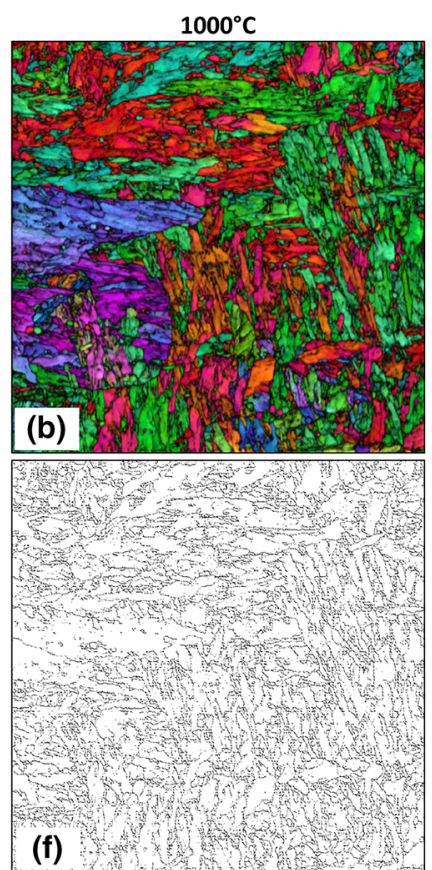
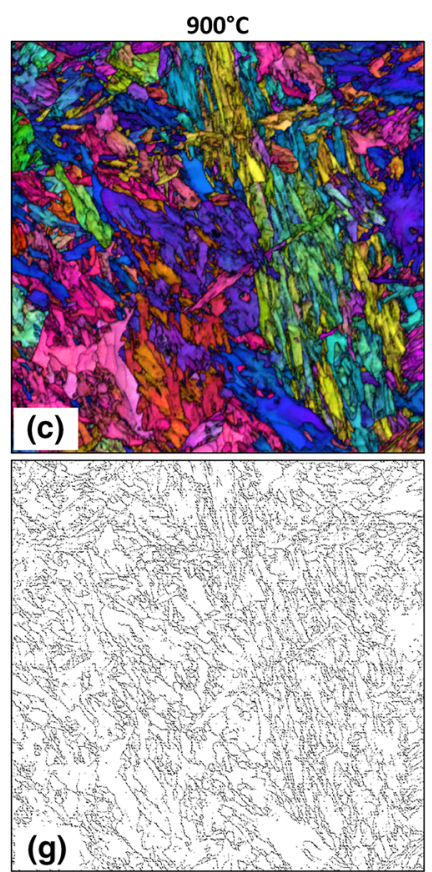
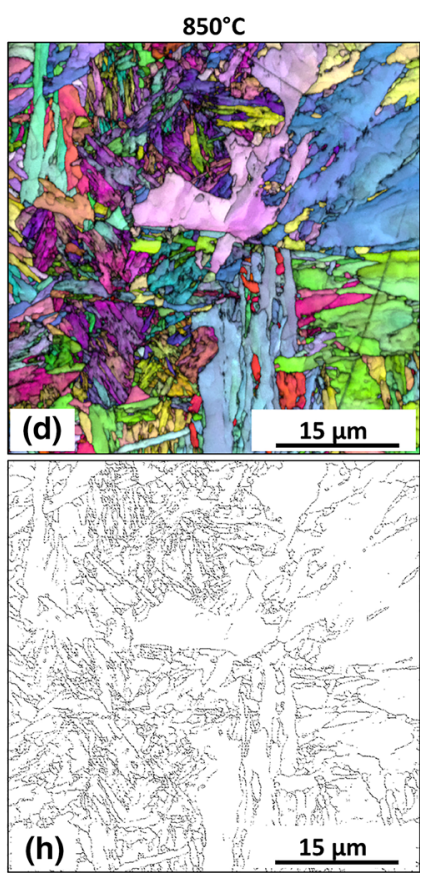

Fig. 9- (a) through $(d)$ Overlaid images of the colored EBSD grain orientation maps and the gray-scale EBSD image quality maps that were collected after weld thermal cycle simulations with a peak temperature of (a) $1523 \mathrm{~K}\left(1250{ }^{\circ} \mathrm{C}\right),\left(\right.$ b) $1273 \mathrm{~K}\left(1000{ }^{\circ} \mathrm{C}\right),(c) 1173 \mathrm{~K}\left(900{ }^{\circ} \mathrm{C}\right)$, and (d) $1123 \mathrm{~K}\left(850^{\circ} \mathrm{C}\right)$. (e) through $(h)$ EBSD grain boundary maps are also included to provide the details of the 2 to 20 and 50 to 60 deg martensitic substructure boundaries.

samples. Figure 11 shows graphs comparing the average number of particles per unit area and their average size in the simulated samples with peak temperatures between $1103 \mathrm{~K}$ and $1523 \mathrm{~K}\left(830{ }^{\circ} \mathrm{C}\right.$ and $\left.1250{ }^{\circ} \mathrm{C}\right)$.
Particles were almost completely dissolved in the simulated sample after the weld thermal cycle simulation with a peak temperature of $1373 \mathrm{~K} \quad\left(1100{ }^{\circ} \mathrm{C}\right)$ (Figure 10(a)), whereas particles were observed in the simulated samples with lower peak temperatures 
(Figures 10(b) through (d)). It is noted that "stringers" of particles were observed after the weld thermal cycle simulation with a peak temperature of $1103 \mathrm{~K}\left(830^{\circ} \mathrm{C}\right)$. These are due to the fact that the particles detected, predominantly the pre-existing $\mathrm{M}_{23} \mathrm{C}_{6}$ carbides in the parent metal, are distributed on lath or grain boundaries that are aligned at approximately $45 \mathrm{deg}$. These particles are able to pin the lath and grain boundaries, which were effectively stabilized and, therefore, likely to result in enhanced creep resistance. Compared to the parent metal sample without exposure to weld thermal cycle simulations (gray shading shown in Figure 11), both a lower number per unit area and a smaller size of secondary precipitate particles were observed in the simulated samples with peak temperatures of $1173 \mathrm{~K}$ and $1273 \mathrm{~K}\left(900{ }^{\circ} \mathrm{C}\right.$ and $\left.1000{ }^{\circ} \mathrm{C}\right)$, whereas the precipitates were completely dissolved upon exposure to the weld thermal cycle with a peak temperature of $1523 \mathrm{~K}$ $\left(1250^{\circ} \mathrm{C}\right)$ (Figure 11). The average size of the particles in the simulated sample with a peak temperature of $1103 \mathrm{~K}\left(830^{\circ} \mathrm{C}\right)$ was found to be slightly larger than the parent metal, whereas the number per unit area of the particles in the same sample was slightly lower than the parent metal (Figure 11).

The relationship between the secondary precipitate particles and the surrounding lath/grain structures in the simulated samples was characterized by using a combined EBSD/ion-beam-induced secondary electron imaging method. Figure 12 shows the EBSD grain boundary map and the ion-beam-induced secondary electron micrographs that were collected from the identical locations in the simulated samples with a peak temperature of $1273 \mathrm{~K}\left(1000{ }^{\circ} \mathrm{C}\right)$ (Figures 12 (a) through (c)) and $1103 \mathrm{~K}\left(830^{\circ} \mathrm{C}\right)$ (Figures 12 (d) through (f)). In the sample, which had experienced a peak temperature of $1273 \mathrm{~K}\left(1000{ }^{\circ} \mathrm{C}\right)$, the substructure boundaries and the PAGBs were found to be barely decorated by the residual secondary precipitate particles after the simulated weld thermal cycle (Figures 12(a) through (c)). However, in the simulated sample with a peak temperature of $1103 \mathrm{~K}\left(830^{\circ} \mathrm{C}\right)$, the secondary precipitate particles were found to be preferentially distributed on the PAGBs and the substructure boundaries (Figures 12(d) through (f)), which are aligned at approximately $45 \mathrm{deg}$.

Precipitates in the simulated parent metal samples were extracted using carbon extraction replicas for chemical analysis at higher resolution in the TEM. Figures 13 and 14 show the representative bright-field STEM micrographs and EDX spectra that were obtained from different particles, respectively.

Fe-rich precipitate particles were observed in the simulated sample with a peak temperature of $1523 \mathrm{~K}$ $\left(1250^{\circ} \mathrm{C}\right)$. These particles were commonly found with an elongated shape with a length of approximately 50 $\mathrm{nm}$. The EDX spectra that were obtained from these particles indicate a chemical composition that is close to the $\mathrm{M}_{3} \mathrm{C}$, cementite, precipitate. ${ }^{[24]} \mathrm{Nb}$ - and V-rich particles were both observed with a size of less than $100 \mathrm{~nm}$, with round and elongated shapes for the $\mathrm{Nb}$ and V-rich particles, respectively. The EDX spectra that were obtained from the $\mathrm{V}$ - and $\mathrm{Nb}$-rich particles indicated a chemical composition close to the MX precipitates. ${ }^{[24,25]} \mathrm{Cr}$-rich particles were found with variable sizes from less than $100 \mathrm{~nm}$ to over $400 \mathrm{~nm}$. The chemical composition of the Cr-rich particles, as indicated by EDX, is similar to that expected from $\mathrm{M}_{23} \mathrm{C}_{6}$ carbides. ${ }^{[25]}$ Thus, it was considered that the precipitate particles as detected by ion-beam-induced secondary electron imaging (e.g., Figures 10 and 12) are predominantly the relatively larger $\mathrm{Cr}$-rich $\mathrm{M}_{23} \mathrm{C}_{6}$ carbides, due to the fact that the other types of precipitates (Fe-, Nb-, and V-rich) are much smaller, with sizes close to or lower than the minimum detectable size using this technique.

The crystallography of the precipitate particles with different chemical compositions was also determined. Figure 15 shows an HR-TEM micrograph that was collected from an Fe-rich precipitate particle in the simulated sample with a peak temperature of $1523 \mathrm{~K}$ $\left(1250{ }^{\circ} \mathrm{C}\right)$ and an FFT of a window of $256 \times 256$ square pixels from this micrograph.

SAED patterns, as shown in Figure 16, were also obtained from the $\mathrm{V}-, \mathrm{Nb}-$, and $\mathrm{Cr}$-rich particles.

Table IV summarizes the different types of precipitate particles that were observed in the parent metal sample that was not exposed to weld thermal cycle simulations and the simulated samples with peak temperatures between $1103 \mathrm{~K}$ and $1523 \mathrm{~K}\left(830^{\circ} \mathrm{C}\right.$ and $\left.1250{ }^{\circ} \mathrm{C}\right)$. $\mathrm{M}_{23} \mathrm{C}_{6}$ carbides and $\mathrm{V}$ - or Nb-rich $\mathrm{MX}$ precipitates were found in the original parent metal sample and the simulated samples exposed to peak temperatures of $1103 \mathrm{~K}$ and $1173 \mathrm{~K}\left(830^{\circ} \mathrm{C}\right.$ and $\left.900{ }^{\circ} \mathrm{C}\right)$. In the sample receiving a peak temperature of $1273 \mathrm{~K}\left(1000^{\circ} \mathrm{C}\right)$, the presence of $\mathrm{M}_{3} \mathrm{C}$ and $\mathrm{MX}$ precipitates was observed, and not $\mathrm{M}_{23} \mathrm{C}_{6}$ carbides, whereas after a peak temperature of $1523 \mathrm{~K}\left(1250{ }^{\circ} \mathrm{C}\right)$, the $\mathrm{M}_{3} \mathrm{C}$ precipitate was the only particle type observed.

Figure 17 shows $\mathrm{Cr}-\mathrm{Nb}-\mathrm{V}$ ternary diagrams showing the variation in the chemical compositions of the MX precipitate particles in the parent metal sample that was not exposed to simulated weld thermal cycles and the simulated samples with a peak temperature of $1173 \mathrm{~K}$ and $1273 \mathrm{~K}\left(900{ }^{\circ} \mathrm{C}\right.$ and $\left.1000{ }^{\circ} \mathrm{C}\right)$. The chemical compositions of the MX precipitates in the simulated samples at $1173 \mathrm{~K}\left(900{ }^{\circ} \mathrm{C}\right)$ were similar to the unexposed parent metal sample, with a continuous range of compositions between $(\mathrm{V}, \mathrm{Cr}) \mathrm{X}$ and $\mathrm{NbX}$. However, in the sample that had experienced a peak temperature of $1273 \mathrm{~K}\left(1000{ }^{\circ} \mathrm{C}\right)$, a larger proportion of $\mathrm{NbX}$ particular was observed within the distribution.

\section{Microstructure in the HAZ of the Grade 92 Bead-on-Plate Weld}

The variation of hardness in the HAZ of the bead-on-plate weld was characterized using hardness mapping analysis. Figure 18 shows a large-scale hardness map that was obtained from the regions of the weld metal, the HAZ, and the parent metal in the bead-onplate weld.

In the region of analysis, a hardness value of over 450 $\mathrm{HV}_{0.2}$ was observed in the HAZ regions that were less than $2 \mathrm{~mm}$ to the weld line. In the regions with a 

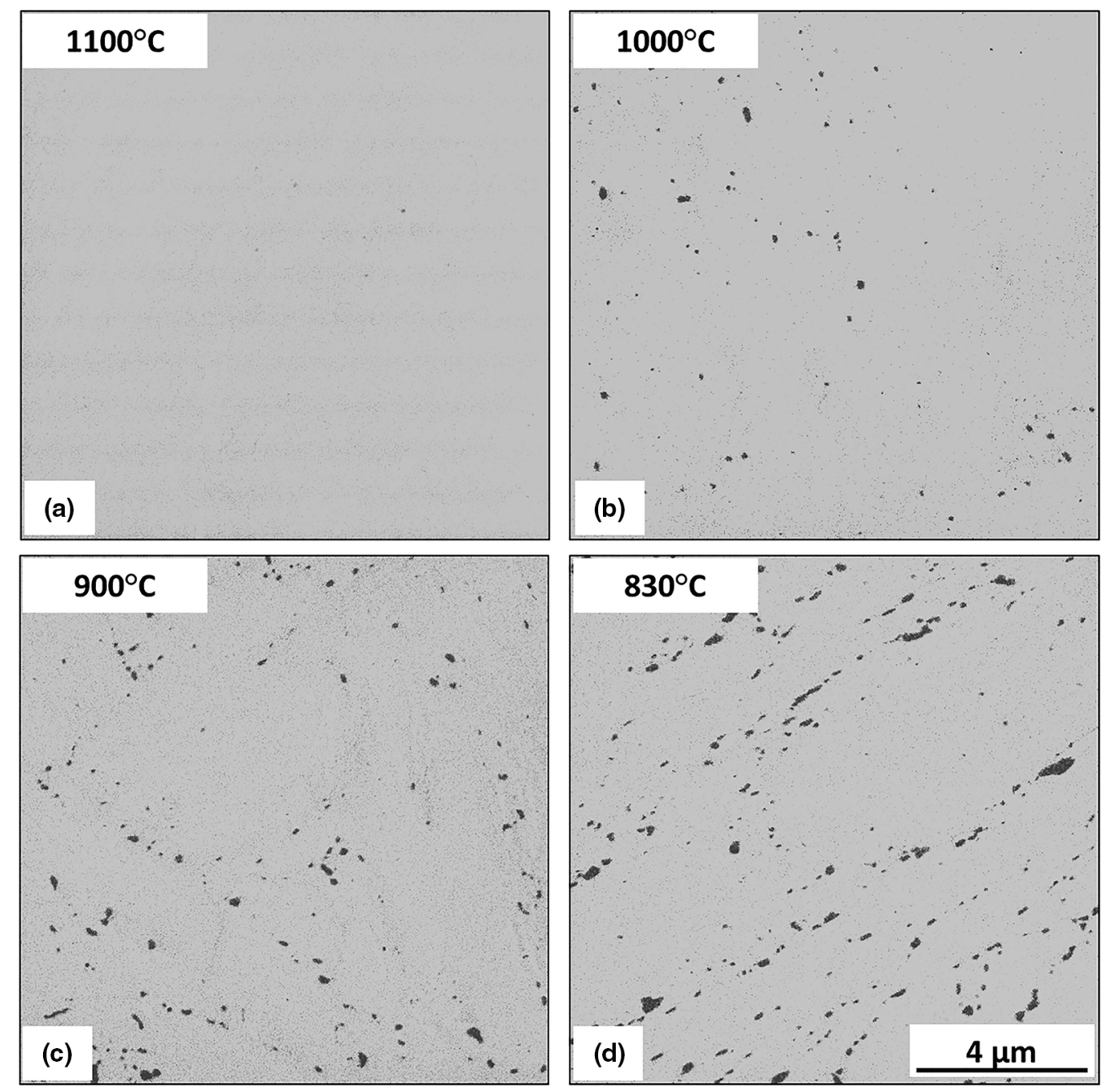

Fig. 10-Ion-beam-induced secondary electron micrographs showing secondary precipitate particles after weld thermal cycle simulations with a peak temperature of $(a) 1373 \mathrm{~K}\left(1100^{\circ} \mathrm{C}\right),(b) 1273 \mathrm{~K}\left(1000{ }^{\circ} \mathrm{C}\right),(c) 1173 \mathrm{~K}\left(900{ }^{\circ} \mathrm{C}\right)$, and $(d) 1103 \mathrm{~K}\left(830^{\circ} \mathrm{C}\right)$.

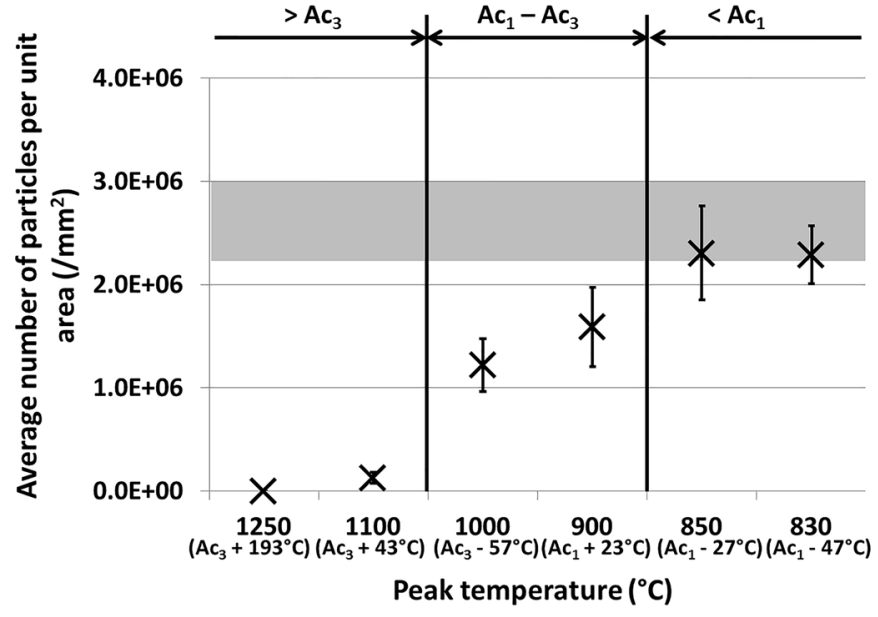

(a)

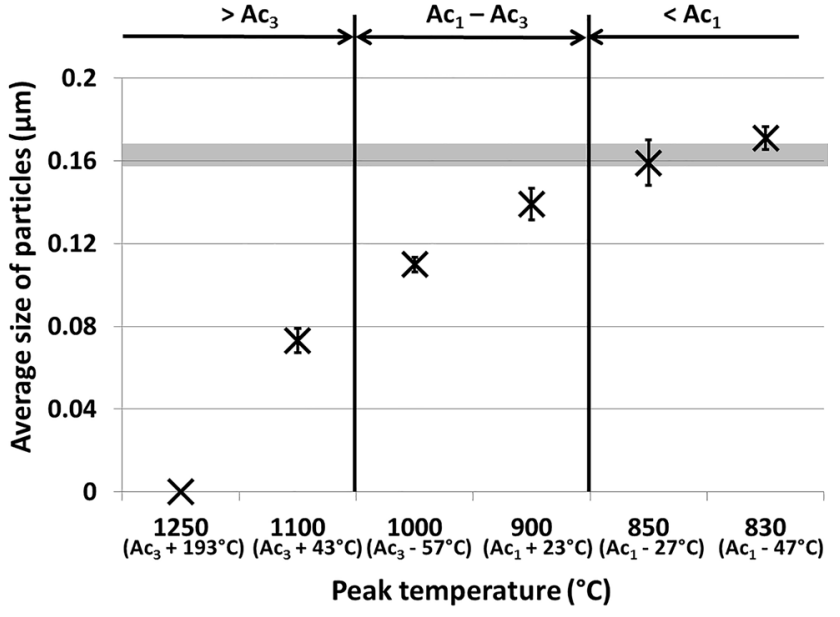

(b)

Fig. 11- Graphs comparing (a) the average number per unit area and $(b)$ the average size of secondary precipitate particles after weld thermal cycle simulations with a peak temperature between $1103 \mathrm{~K}$ and $1523 \mathrm{~K}\left(830^{\circ} \mathrm{C}\right.$ and $\left.1250{ }^{\circ} \mathrm{C}\right)$. The gray boxes indicate the number per unit area and size of particles in the parent metal without exposure to weld thermal cycle simulations. The number per unit area and the size of particles were measured by gray scale segmentation using the ImageJ software. 

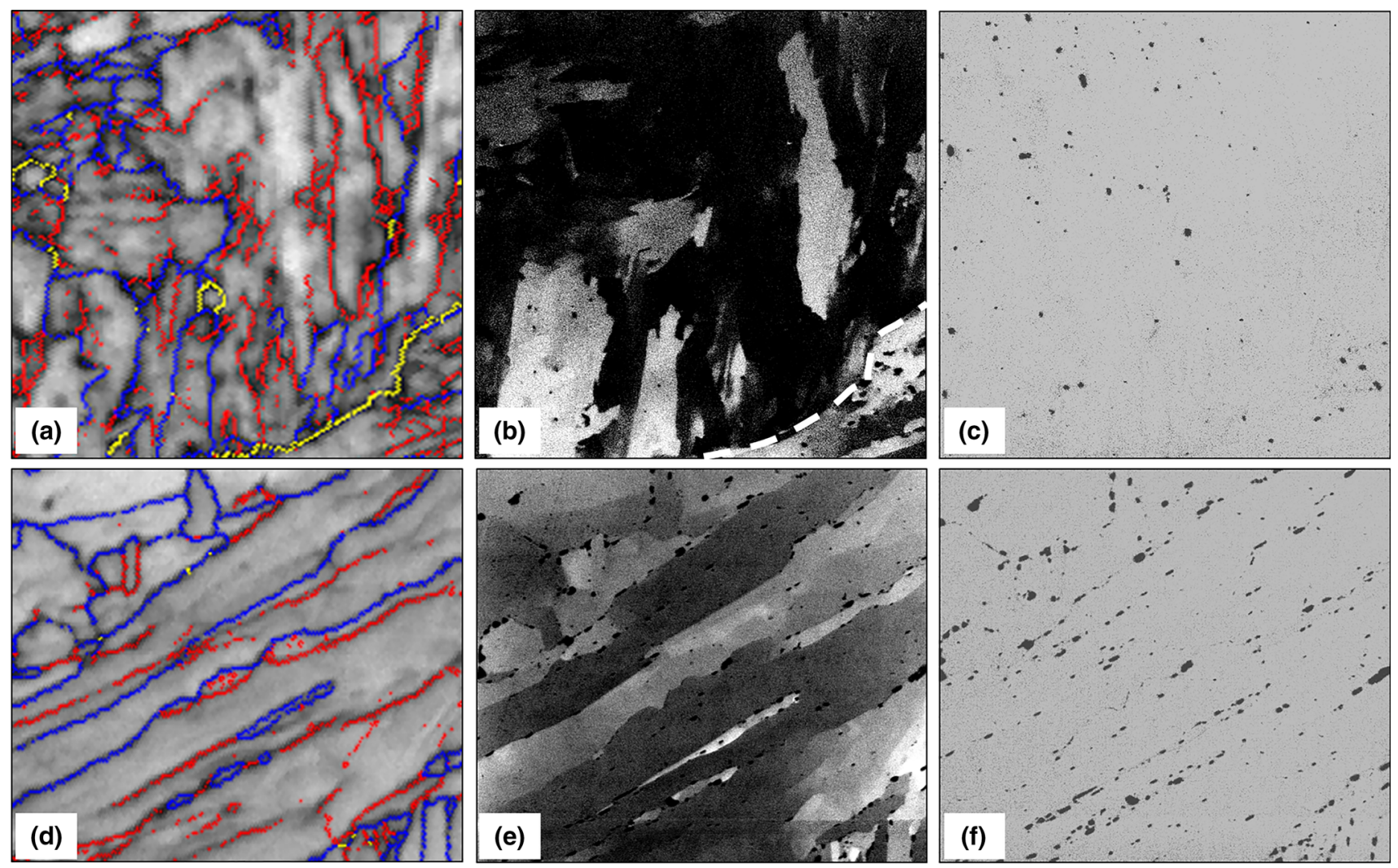

$-2^{\circ}-20^{\circ}-20^{\circ}-50^{\circ}=50^{\circ}-60^{\circ}$

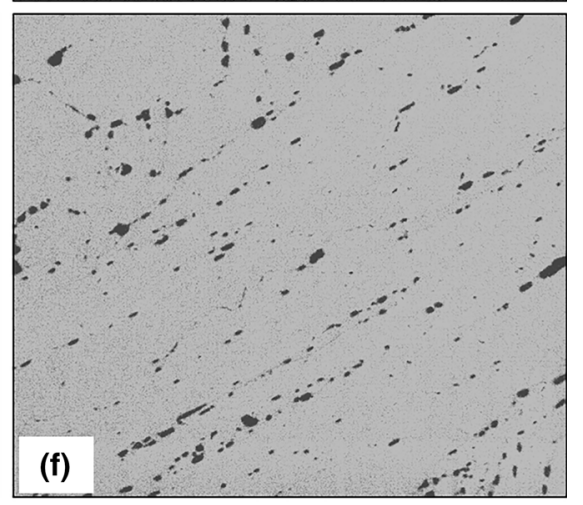

$4 \mu \mathrm{m}$

Fig. 12- (a) and (d) EBSD grain boundary maps and $(b),(c),(e)$, and $(f)$ ion-beam-induced secondary electron micrographs that were collected from identical regions after weld thermal cycle simulations with a peak temperature of (a) through (c) $1273 \mathrm{~K}\left(1000{ }^{\circ} \mathrm{C}\right)$ and (d) through (f) $1103 \mathrm{~K}\left(830^{\circ} \mathrm{C}\right)$. The dashed line in (b) indicates the position of the 20 to 50 deg PAGB in (a).
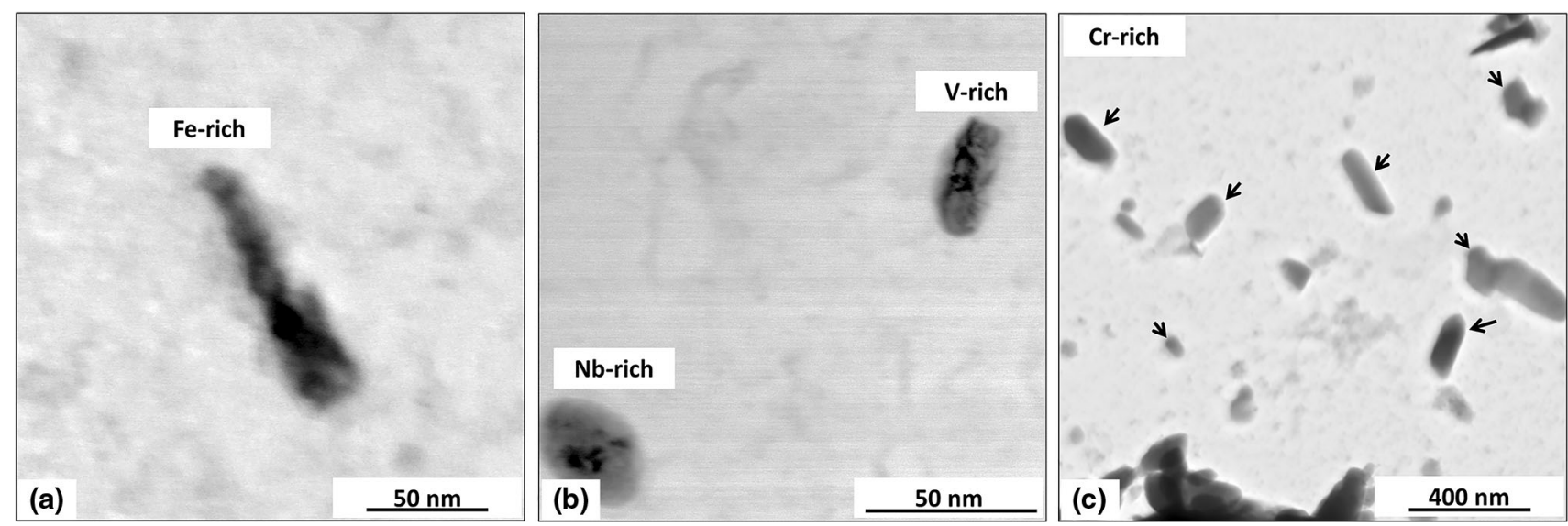

Fig. 13-Bright-field STEM micrographs showing $(a)$ an Fe-rich precipitate particle, $(b) \mathrm{V} / \mathrm{Nb}$-rich particles, and $(c)$ Cr-rich particles (indicated by black arrows).

distance of over $2 \mathrm{~mm}$ from the weld line, the hardness in the HAZ decreased from over $450 \mathrm{HV}_{0.2}$ to 210 to 240 $\mathrm{HV}_{0.2}$ as the distance from the weld line increased. The parent metal hardness was in the band 210 to $240 \mathrm{HV}_{0.2}$, with the weld metal hardness over $420 \mathrm{HV}_{0.2}$. The variation of the grain structure across the HAZ was characterized using EBSD mapping analysis. Figure 19 shows a large-scale montage of EBSD grain orientation maps that provides an overview of the grain structure in the regions of the weld metal, the HAZ, and the parent metal in the bead-on-plate weld.

EBSD mapping analyses were performed at higher magnifications to characterize the grain structure in the different regions of the HAZ in more detail. Figure 20 shows the overlaid images of the colored EBSD grain orientation maps and the gray-scale EBSD image 


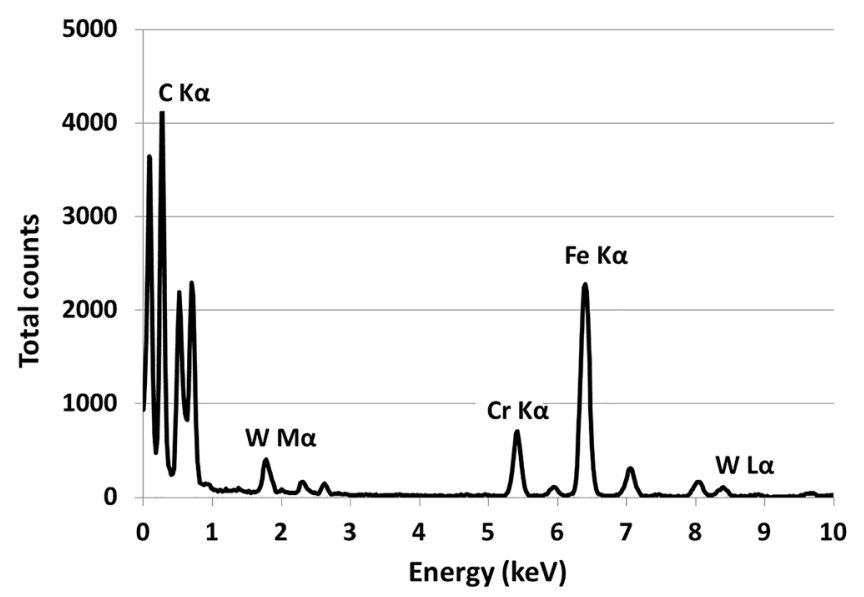

(a)

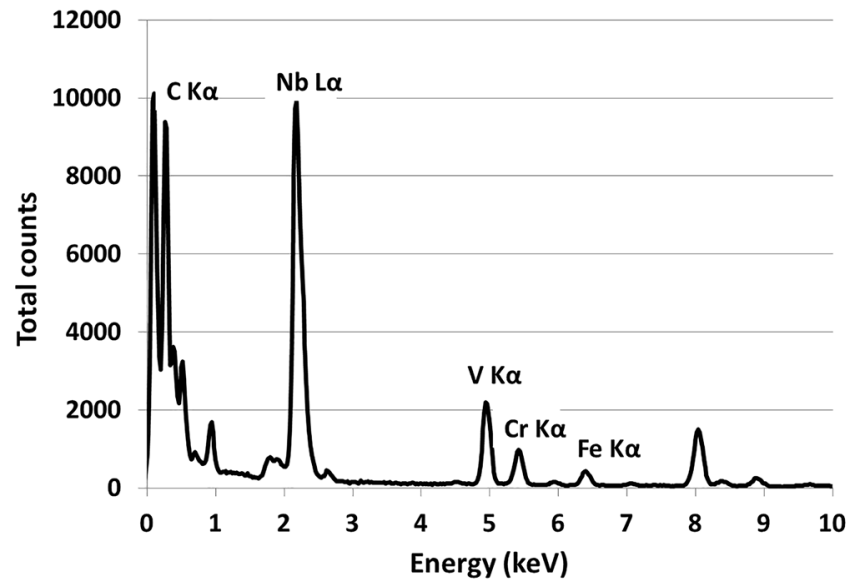

(c)

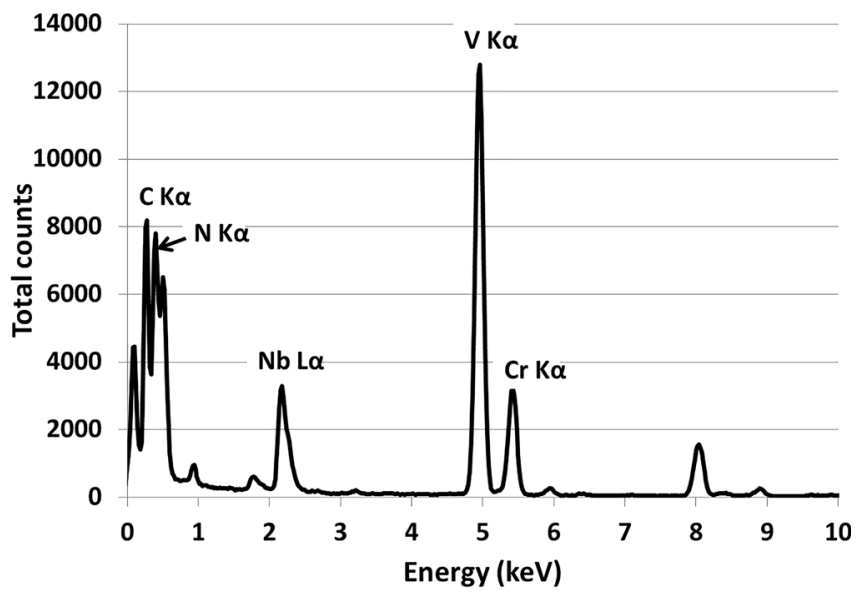

(b)

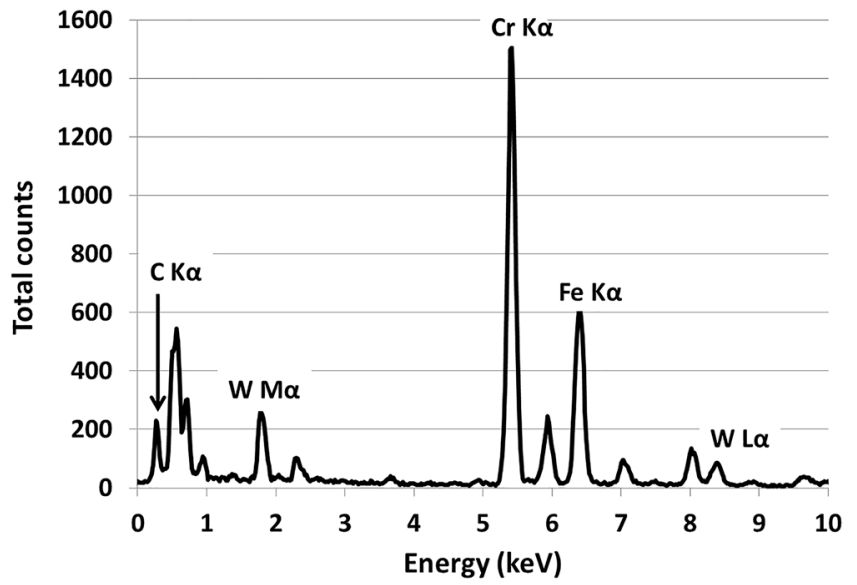

(d)

Fig. 14 - Representative EDX spectra showing the chemical compositions of $(a)$ an Fe-rich, $(b)$ a V-rich, $(c)$ a Nb-rich, and $(d)$ a Cr-rich particle.
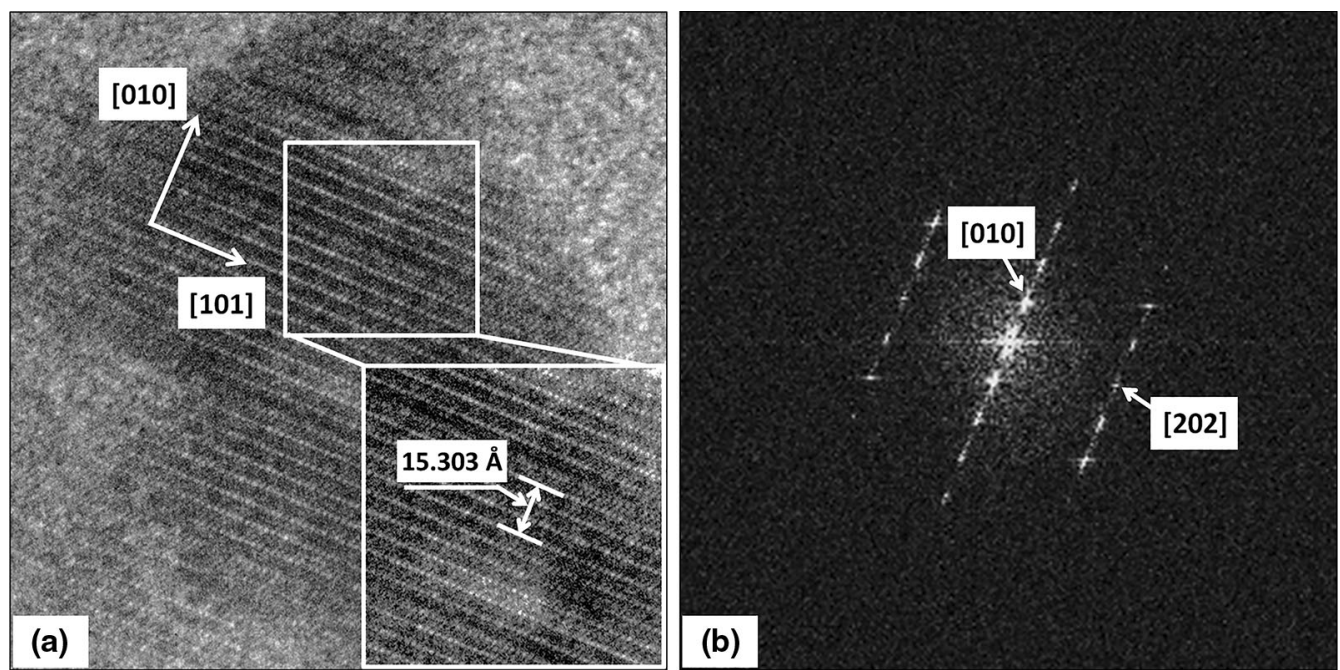

Fig. 15-(a) An HR-TEM micrograph that was collected from an Fe-rich precipitate particle. (b) FFT of a window with a size of $256 \times 256$ square pixels, as shown by the inset in (a).

quality maps that were collected at a step size of $1 \mu \mathrm{m}$ and the EBSD grain boundary maps showing the 20 to $50 \mathrm{deg}$ boundary in the identical regions.
In regions within approximately $1.5 \mathrm{~mm}$ of the weld line, the grain size in the HAZ was found to be significantly smaller in size than the parent metal 

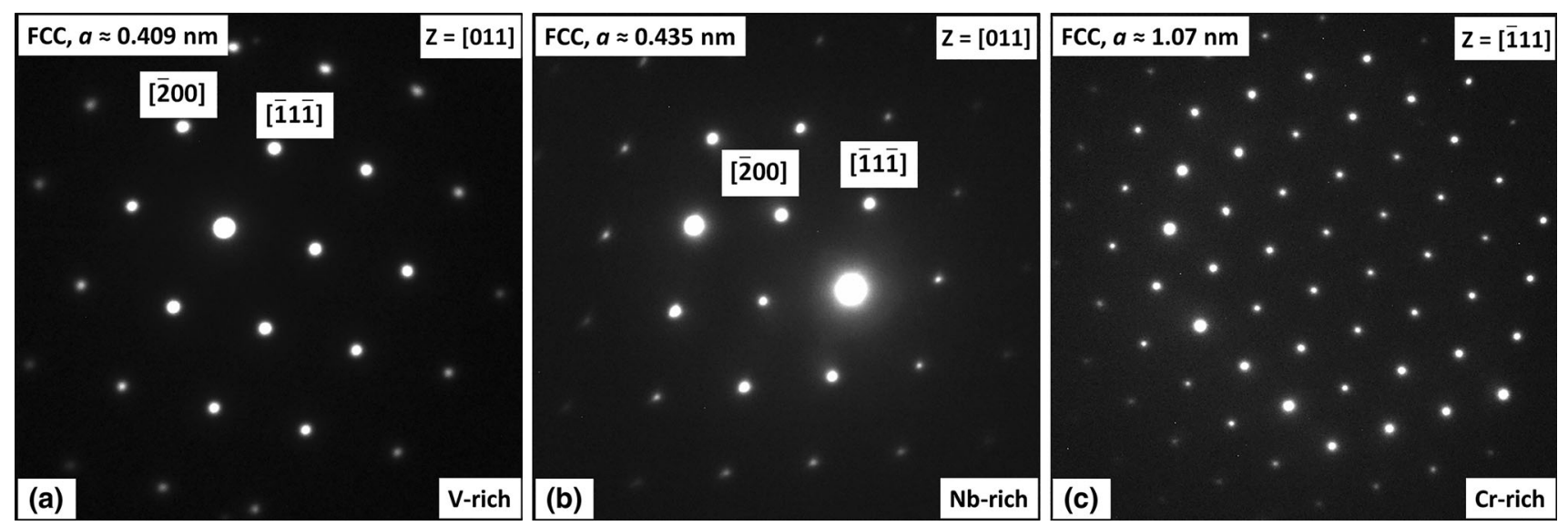

Fig. 16-SAED patterns that were obtained from $(a)$ a V-rich particle, $(b)$ a Nb-rich particle, and $(c)$ a Cr-rich particle.

Table IV. Different Types of Precipitate Particles That Were Observed in Both the Parent Metal Sample and Each of the Simulated Samples, Which Experienced Peak Temperatures Between $1103 \mathrm{~K}$ and $1523 \mathrm{~K}\left(830{ }^{\circ} \mathrm{C}\right.$ and $\left.1250{ }^{\circ} \mathrm{C}\right)$

\begin{tabular}{lcccrr}
\hline Samples & $1523 \mathrm{~K}\left(1250^{\circ} \mathrm{C}\right)$ & $1273 \mathrm{~K}\left(1000{ }^{\circ} \mathrm{C}\right)$ & $1173 \mathrm{~K}\left(900{ }^{\circ} \mathrm{C}\right)$ & $1103 \mathrm{~K}\left(830^{\circ} \mathrm{C}\right)$ & Parent $\mathrm{Metal}$ \\
\hline Precipitates & $\mathrm{M}_{3} \mathrm{C}$ & $\mathrm{M}_{3} \mathrm{C}, \mathrm{MX}$ & $\mathrm{M}_{23} \mathrm{C}_{6}, \mathrm{MX}$ & $\mathrm{M}_{23} \mathrm{C}_{6}, \mathrm{MX}$ & $\mathrm{M}_{23} \mathrm{C}_{6}, \mathrm{MX}$ \\
\hline
\end{tabular}

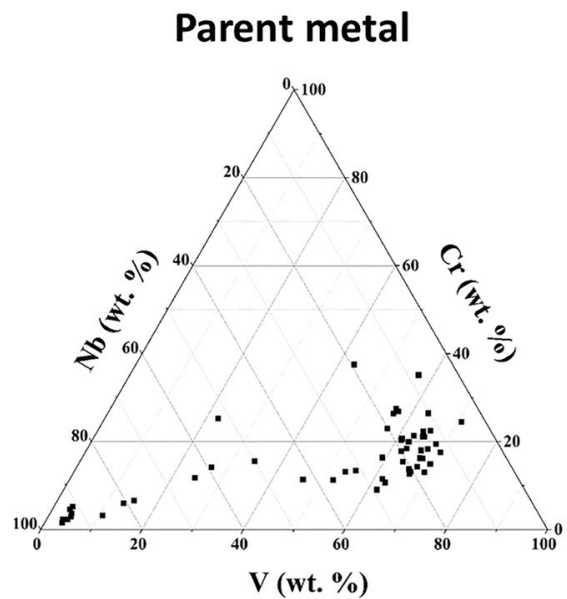

(a)

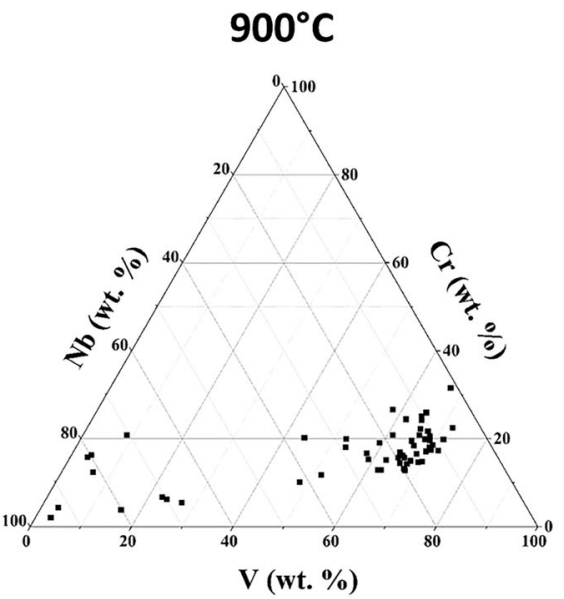

(b)

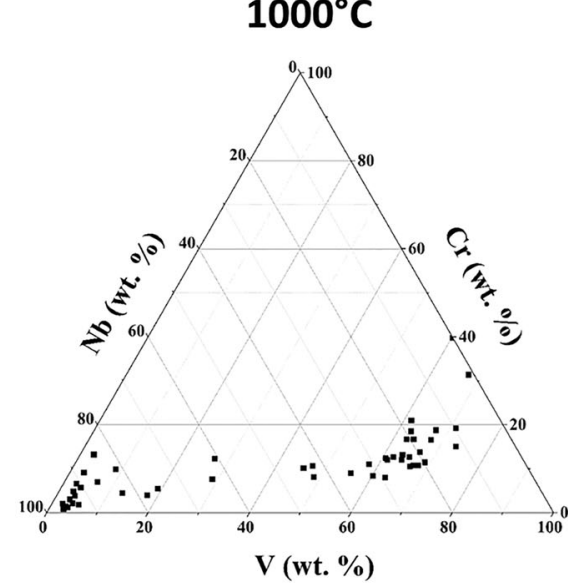

(c)

Fig. 17-(a) Cr-Nb-V ternary diagrams comparing the chemical composition of the MX precipitates in the parent metal to the simulated samples after weld thermal cycle simulations with a peak temperature of $(b) 1173 \mathrm{~K}\left(900{ }^{\circ} \mathrm{C}\right)$ and $(c) 1273 \mathrm{~K}\left(1000^{\circ} \mathrm{C}\right)$. The total numbers of the particles that were investigated in each sample are (a) 53, (b) 56, and (c) 48.

(Figure 19). The presence of PAGs with a size of over 50 $\mu \mathrm{m}$ was observed in the regions with a distance of less than $0.5 \mathrm{~mm}$ from the weld line (Figures 20(a) and (d)), whereas the PAGs in the region within a distance of 0.5 to $1.1 \mathrm{~mm}$ from the weld line were predominantly found with a size of 10 to $20 \mu \mathrm{m}$ (Figures 20(b) and (e)). The grain structure in the region within a distance of $1.6 \mathrm{~mm}$ from the weld line is composed of PAGs with a size of less than $10 \mu \mathrm{m}$ in the regions together with coarse lathlike grains with a width of $5 \mu \mathrm{m}$ (Figures 20(c) and (f)).

EBSD analyses were conducted under a higher magnification to provide details of the martensitic substructure. Figure 21 shows the overlaid images of the colored EBSD grain orientation maps and the gray-scale EBSD image quality maps that were collected at a step size of $0.1 \mu \mathrm{m}$ and the EBSD grain boundary maps showing the 2 to 20 and 50 to 60 deg boundaries.

In the regions that are less than $0.1 \mathrm{~mm}$ from the weld line, the martensitic substructure is predominantly composed of laths with a width of less than $5 \mu \mathrm{m}$ (Figures 21(a) and (d)), whereas a finer substructure was observed in the regions further away from the weld line (Figures 21(b) and (e)). In the regions showing a duplex microstructure due to partial reaustenization, the substructures in the reaustenitized grains were much finer 
than the original substructure in the parent metal, which is composed of the laths with a width of up to $10 \mu \mathrm{m}$ (Figures 21(c) and (f)).

Ion-beam-induced secondary electron imaging was performed to investigate the distribution of precipitate particles. Figure 22 shows the ion-beam-induced secondary electron micrographs that were collected across the HAZ of the bead-on-plate weld. The number of secondary precipitate particles per unit area and the size of particles were both quantitatively measured from ion-beam-induced secondary electron micrographs. Figure 23 shows the graphs showing the variations of the number per unit area and the size of precipitate particles across the HAZ of the bead-on-plate weld in the identical regions where EBSD mapping analyses were previously performed.

Particles were not observed in the regions within a distance of less than $0.7 \mathrm{~mm}$ from the weld line (Figures 22(a) and 23(a)). The average number per unit area and the average size of particles were found to both increase as the distance from the weld line increased from 0.85 to $1.6 \mathrm{~mm}$.

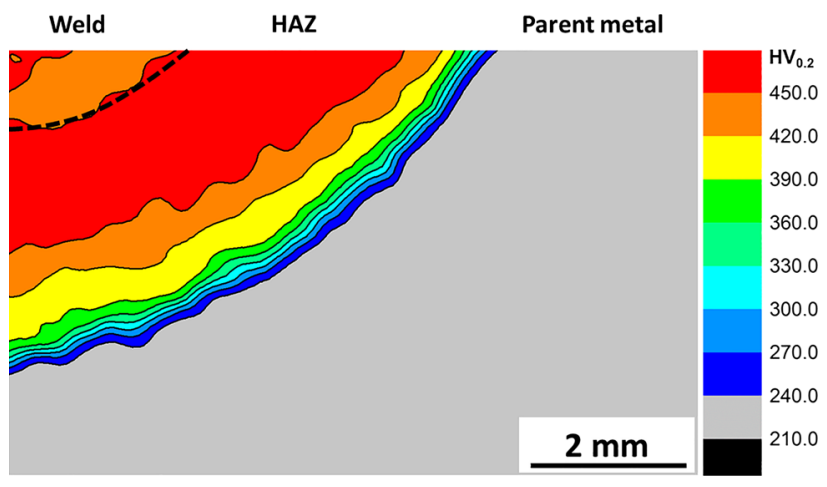

Fig. 18-Large-scale hardness map showing the variation of hardness in an as-welded single-pass bead-on-plate Grade 92 weld. The dashed line indicates the weld line. The region where hardness mapping analysis was performed is indicated by the gray box in Fig. 4 .

\section{DISCUSSION}

The experimentally measured $A c_{1}$ and the $A c_{3}$ temperatures (Table III) were found to be higher than the values of the $A e_{1}$ and the $A e_{3}$ temperatures predicted by thermodynamic calculations, with a greater difference observed between $A c_{3}$ and $A e_{3}$ than between $A c_{1}$ and $A e_{1}$. Published values for Grade 92 steel are typically in the range $A c_{1}: 1073 \mathrm{~K}$ to $1108 \mathrm{~K}\left(800{ }^{\circ} \mathrm{C}\right.$ to $\left.835^{\circ} \mathrm{C}\right)$ and $A c_{3}: 1173 \mathrm{~K}$ to $1193 \mathrm{~K}\left(900{ }^{\circ} \mathrm{C}\right.$ to $\left.920{ }^{\circ} \mathrm{C}\right) \cdot{ }^{[4,26]}$ However, in other recent work concerned with HAZ simulations in 9Cr steel welds (e.g., References 8 and 20), the measured values of the $A c_{1}$ and $A c_{3}$ temperatures during weld thermal cycles were also found to be higher than published data that were obtained by using a relatively low heating rate (e.g., $28 \mathrm{~K} / \mathrm{h}\left(28^{\circ} \mathrm{C} / \mathrm{h}\right) \approx 0.0078 \mathrm{~K} / \mathrm{s}$ $\left(0.0078{ }^{\circ} \mathrm{C} / \mathrm{s}\right)$, as defined by ASTM A1033-04 $\left.{ }^{[27]}\right)$. However, in order to reproduce the microstructures observed in practical welding processes, in which heating rates of over $100 \mathrm{~K} \mathrm{~s}^{-1}\left(100{ }^{\circ} \mathrm{C} \mathrm{s}^{-1}\right)$ can be applied, ${ }^{[28]}$ it is important to consider the influence of heating rate on the $A c_{1}$ and $A c_{3}$ temperatures. It is worth noting that according to a systematic investigation of the variation in heating rate on the $A c_{1}$ and $A c_{3}$ temperatures of Grade 92 steel, ${ }^{[29]}$ the $A c_{1}$ and $A c_{3}$ temperatures of Grade 92 steel were relatively stable at lower heating rates up to $0.3 \mathrm{~K} \mathrm{~s}^{-1}\left(0.3{ }^{\circ} \mathrm{C} \mathrm{s}^{-1}\right)$, whereas at heating rates of over $10 \mathrm{~K} \mathrm{~s}^{-1}\left(10^{\circ} \mathrm{C} \mathrm{s}^{-1}\right)$, the measured $A c_{1}$ and $A c_{3}$ temperatures were observed to increase significantly. Therefore, the higher measured values of the $A c_{1}$ and $\mathrm{Ac}_{3}$ temperatures in this case are attributable to the high heating rates used to simulate the weld thermal cycles.

Similarities in grain structure were observed between the regions that were less than $0.5 \mathrm{~mm}$ from the weld line in the HAZ of the bead-on-plate sample (Figures 20(a) and 21(a)) and the simulated samples that were heated to a temperature above the $A c_{3}$ temperature [e.g., $1523 \mathrm{~K}\left(1250^{\circ} \mathrm{C}\right)$ ] (Figures $8(\mathrm{a})$ and $\left.9(\mathrm{a})\right)$. The grain structure in the regions further away from the weld line (Figures 20(b) and 21(b)) was found to be similar to the simulated sample, which was heated to a temperature close to the $A c_{3}$ temperature (e.g., $\left.1273 \mathrm{~K}\left(1000^{\circ} \mathrm{C}\right)\right)$ (Figures $8(\mathrm{~b})$ and $9(\mathrm{~b})$ ). In the regions close to the

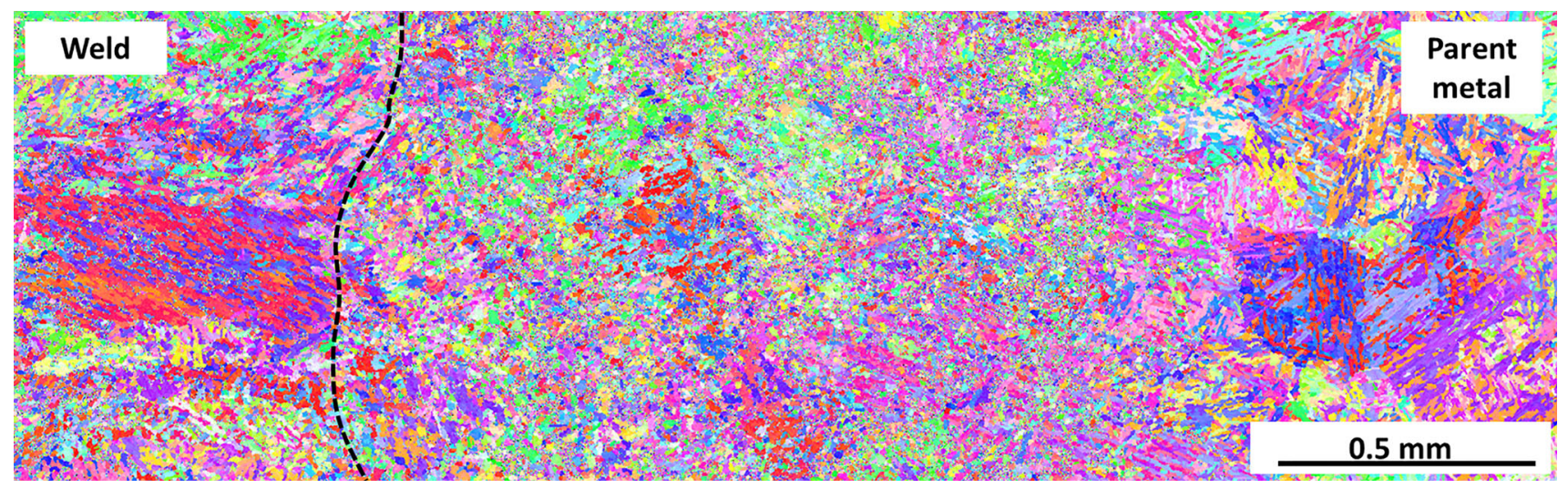

Fig. 19-Large-scale montage of EBSD grain orientation maps providing an overview of an as-welded single-pass bead-on-plate Grade 92 weld. The dashed line indicates the weld line. The region where EBSD analyses were performed is indicated by the white box in Fig. 4 . 

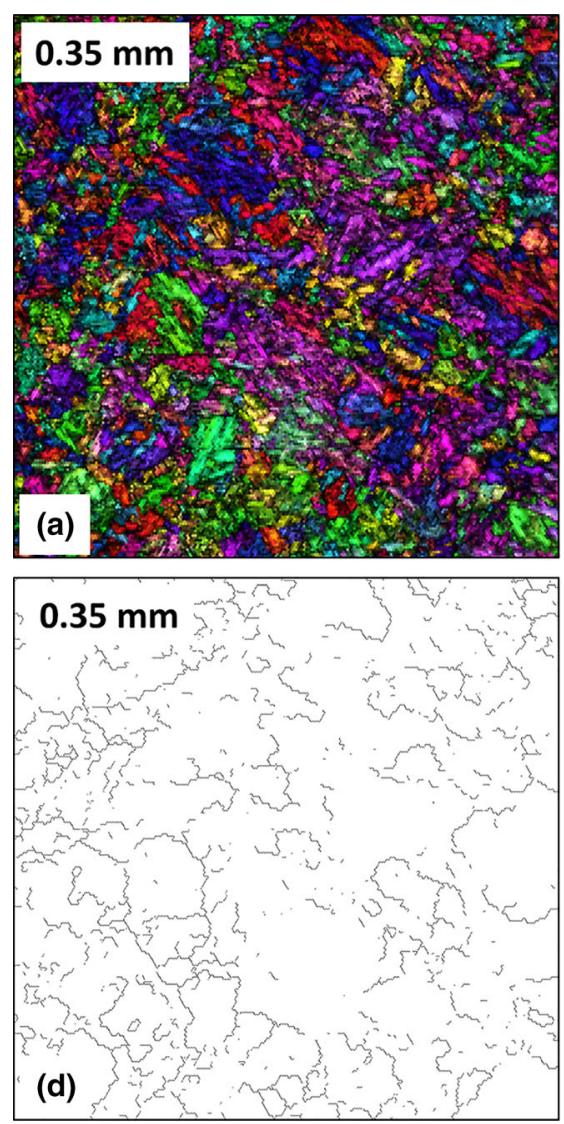
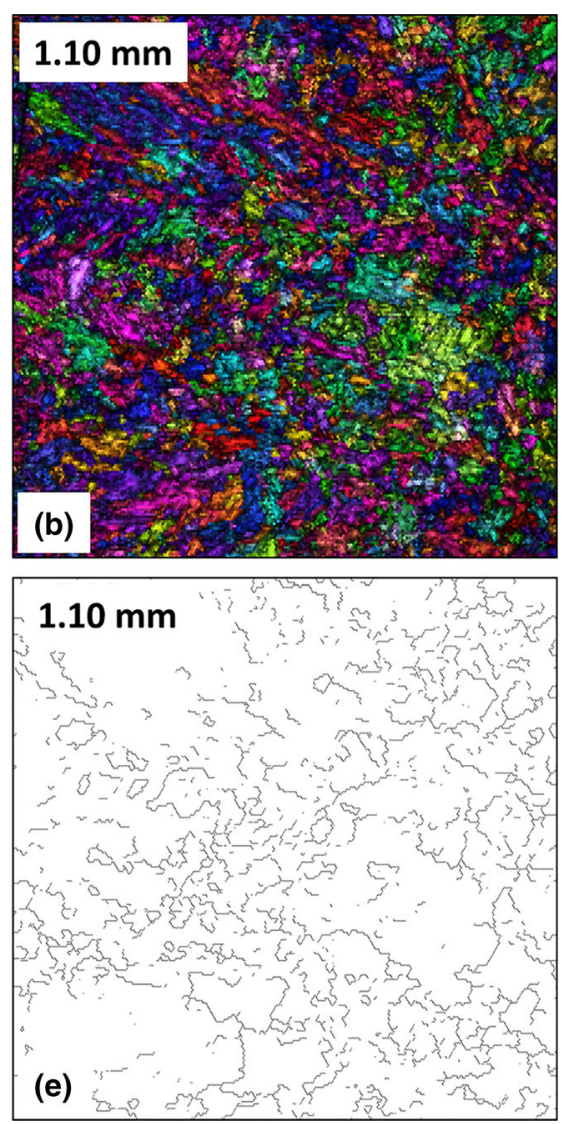
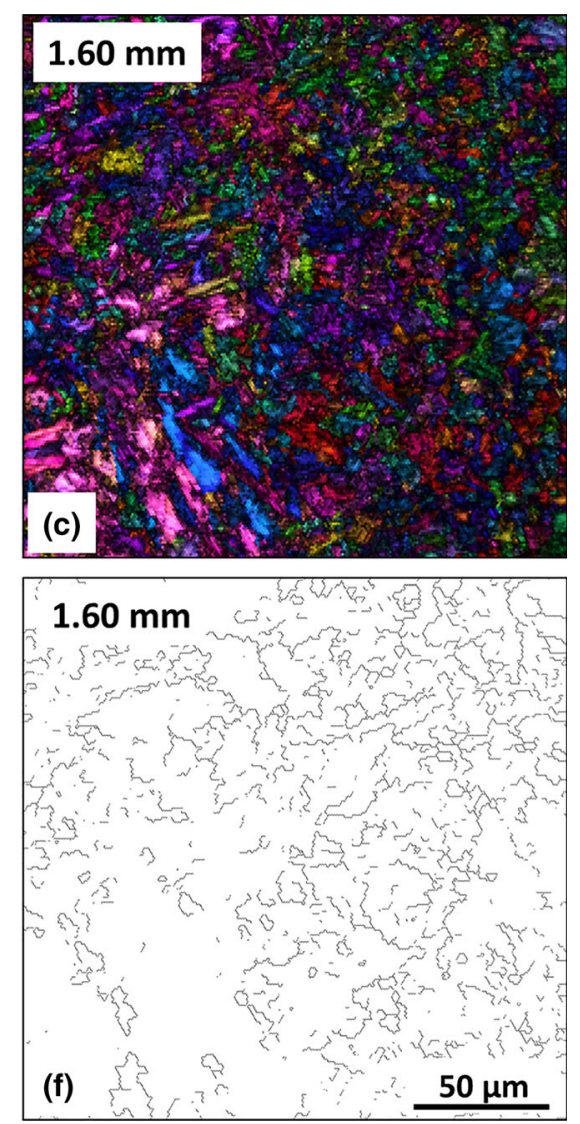

Fig. 20-(a) through $(c)$ Overlaid images of the colored EBSD grain orientation and the gray-scale EBSD image quality maps showing the PAG structure in the regions with a distance of (a) $0.35 \mathrm{~mm}$, (b) $1.10 \mathrm{~mm}$, and (c) $1.60 \mathrm{~mm}$ from the weld line. (d) through $(f)$ EBSD grain boundary maps showing the 20 to $50 \mathrm{deg}$ boundary in the identical regions are also included.

boundary between the HAZ and the parent metal (Figures 20(c) and 21(c)), the grain structure was found to be similar to the simulated sample, which experienced an intercritical peak temperature between the $A c_{1}$ and $A c_{3}$ temperatures (Figures 8(c), (d) and 9(c), (d)).

The hardness in the completely reaustenitized regions was found to be significantly higher than the parent metal (Figure 18), which is due to the fact that the microstructure in these regions is predominantly composed of the freshly formed untempered martensite that is associated with a higher hardness, compared to the tempered martensitic microstructure of the original parent metal.

Precipitates were not detected by ion-beam-induced secondary electron imaging in the regions with a distance of less than $0.6 \mathrm{~mm}$ from the weld line (Figure 22(a)), which is similar to the observations from the simulated parent metal sample with a peak temperature of $1523 \mathrm{~K}\left(1250^{\circ} \mathrm{C}\right)$ (Figure 11). Detailed particle analysis on carbon extraction replicas indicated that a heating cycle to these high temperatures resulted in complete dissolution of both the $\mathrm{M}_{23} \mathrm{C}_{6}$ carbides and the MX precipitates. The absence of precipitate particles in the ion-beam-induced secondary electron micrographs is, thus, due to the complete dissolution of pre-existing precipitates, such as the $\mathrm{M}_{23} \mathrm{C}_{6}$ carbides and the MX precipitates, upon an exposure to the weld thermal cycle with high peak temperatures. In addition, nanosize Fe-rich $\mathrm{M}_{3} \mathrm{C}$ precipitates were observed by TEM in the same simulated parent metal sample (Figure 13). Due to the small sizes of $\mathrm{M}_{3} \mathrm{C}$ precipitate particles, they were, indeed, not detectable by the ion-beam-induced secondary electron imaging. $\mathrm{M}_{3} \mathrm{C}$ precipitates were not observed in the original parent metal samples; therefore, they do not exist in the initial microstructure of the parent metal but are formed during the weld thermal cycle simulations as a result of autotempering during cooling.

As the distance from the weld line further increased beyond $0.8 \mathrm{~mm}$, undissolved secondary precipitate particles were observed (Figure 22(b)). The highest peak temperature at which undissolved precipitates were observed after the weld thermal cycle simulations was $1273 \mathrm{~K}\left(1000^{\circ} \mathrm{C}\right)$ (Figure 11). Detailed particle analysis on the carbon extraction replicas from this sample shows that the undissolved precipitates after the simulated weld thermal cycle are mainly of the MX type, with the $\mathrm{M}_{23} \mathrm{C}_{6}$ carbides having been almost completely dissolved (Table IV). This is consistent with observations in the literature for Grade 92 steel that the $\mathrm{M}_{23} \mathrm{C}_{6}$ carbides are not stable at temperatures over $1273 \mathrm{~K}$ $\left(1000{ }^{\circ} \mathrm{C}\right),{ }^{[5]}$ and indeed the predicted dissolution 

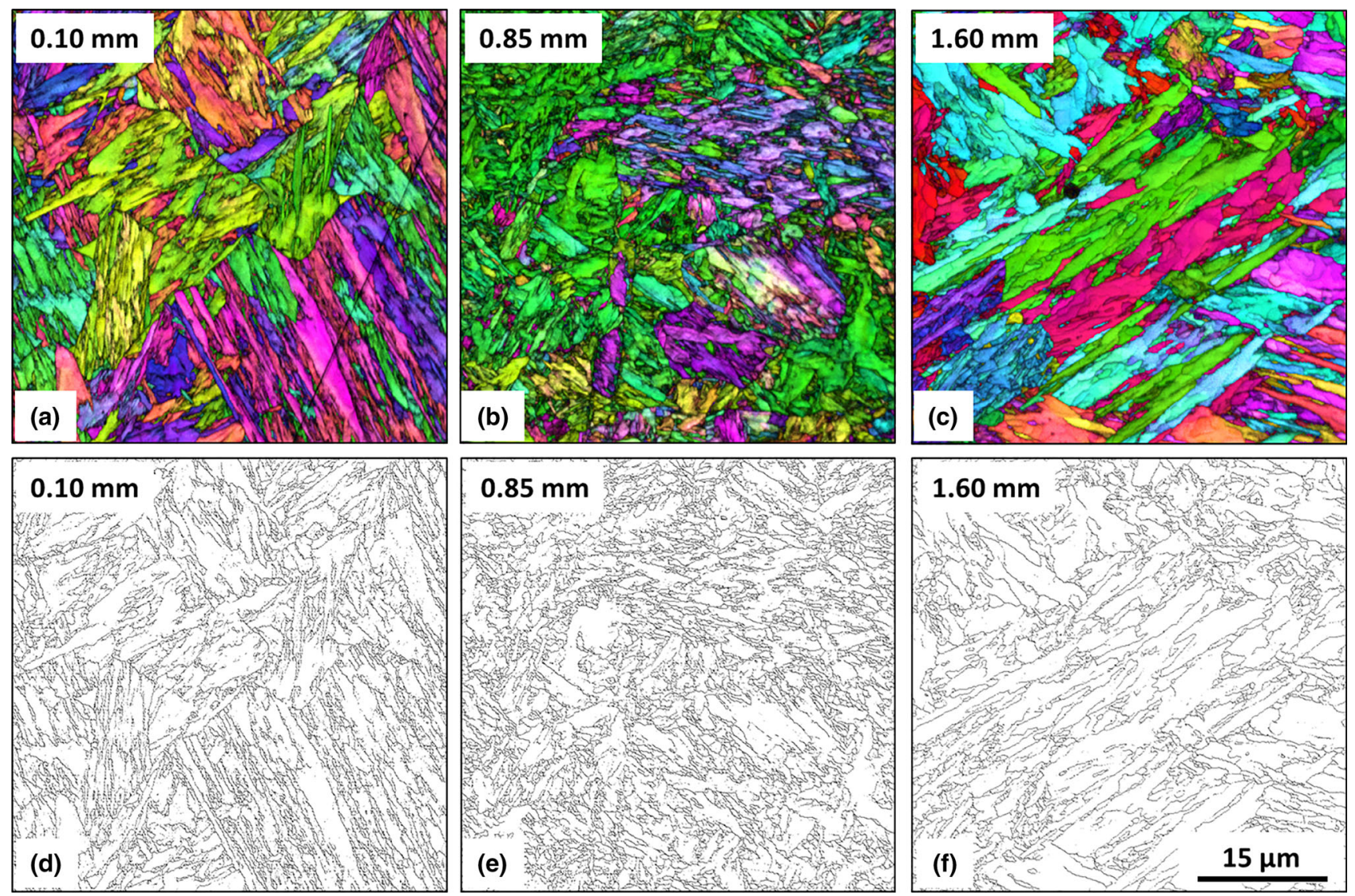

Fig. 21-(a) through $(c)$ Overlaid images of the colored EBSD grain orientation and the gray-scale EBSD image quality maps showing the martensitic substructure in the regions with a distance of (a) $0.10 \mathrm{~mm},(b) 0.85 \mathrm{~mm}$, and (c) $1.60 \mathrm{~mm}$ from the weld line. (d) through $(f)$ The EBSD grain boundary maps showing the 2 to 20 and 50 to 60 deg boundaries are also included.
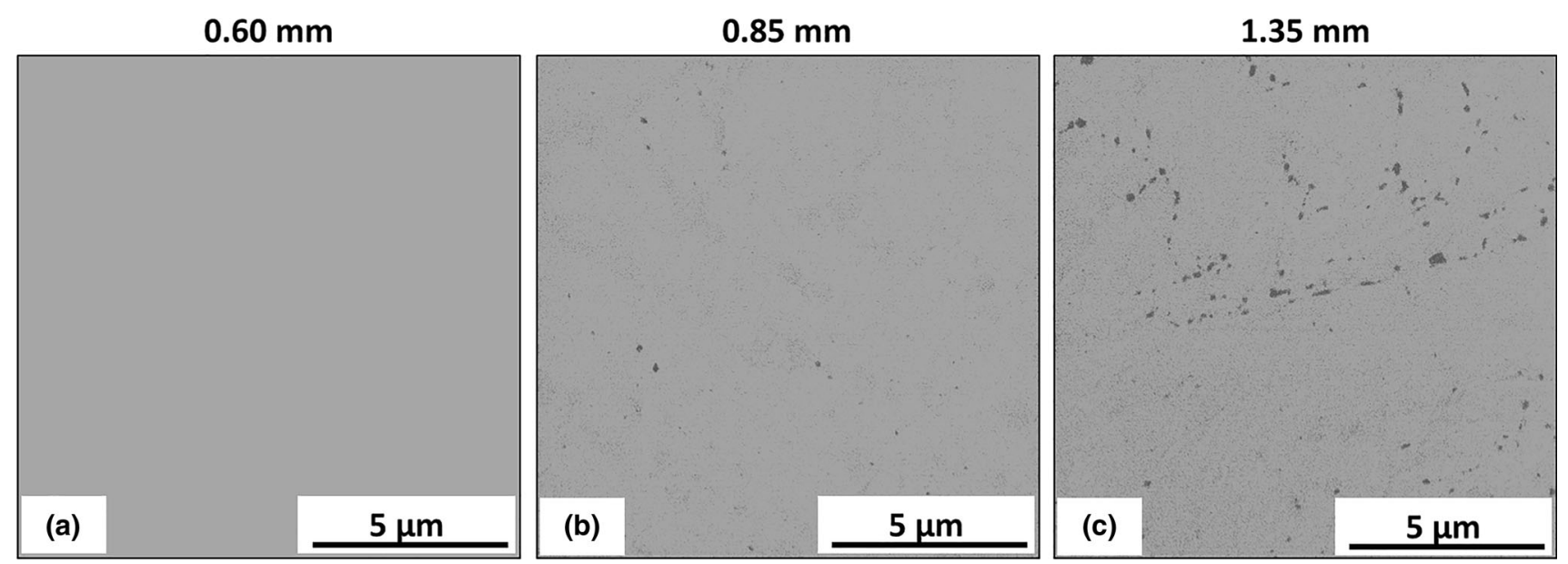

Fig. 22-Ion-beam-induced secondary electron micrographs showing secondary precipitate particles in the regions with a distance of (a) $0.60 \mathrm{~mm},(b) 0.85 \mathrm{~mm}$, and (c) $1.35 \mathrm{~mm}$ from the weld line in an as-welded single-pass bead-on-plate Grade 92 weld.

temperature of $\mathrm{M}_{23} \mathrm{C}_{6}$ carbides in Grade 92 steel is $\sim 1163 \mathrm{~K}\left(890{ }^{\circ} \mathrm{C}\right)$ according to thermodynamic equilibrium calculations. ${ }^{[27]}$

It was possible to compare the ion-beam-induced secondary electron micrographs with EBSD analysis of identical regions (Figure 12), which has shown that these undissolved particles are not closely associated with PAGBs or substructure boundaries. This observation suggests that these undissolved precipitate particles do not have a significant influence on the resulting grain structure after the weld thermal cycle simulations.

It was also noted that in the simulated sample that had experienced a peak temperature of $1273 \mathrm{~K}$ 


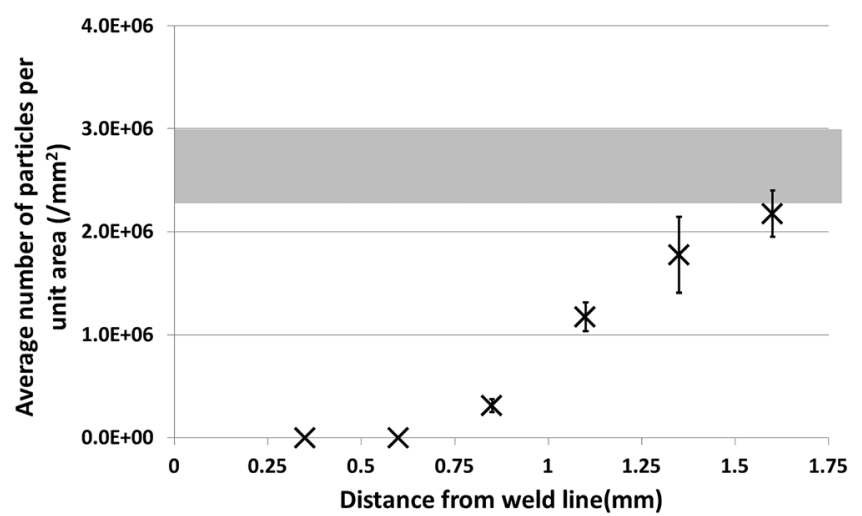

(a)

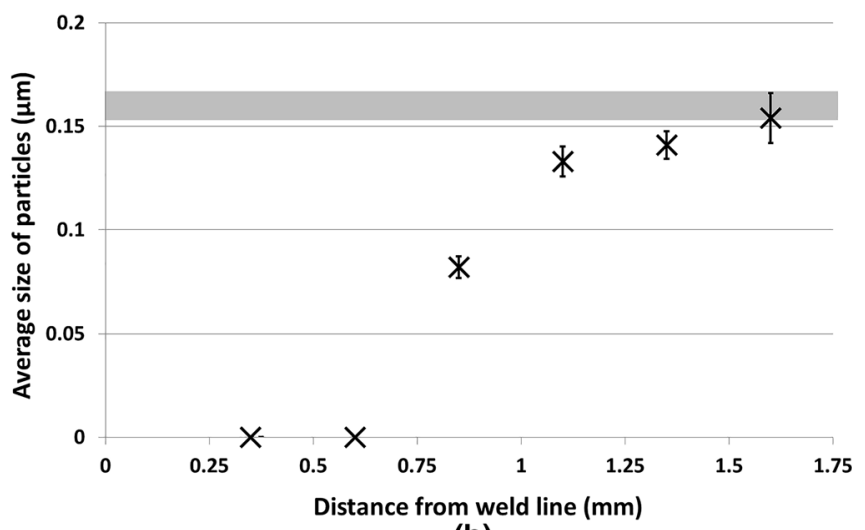

(b)

Fig. 23 - Graphs showing the variations of $(a)$ the average number per unit area and $(b)$ the average size of the secondary precipitate particles across the HAZ of an as-welded single-pass bead-on-plate Grade 92 weld. The gray boxes indicate the number of particles per unit area and the size of particles in the parent metal. Particles were measured by gray scale segmentation using the ImageJ software.

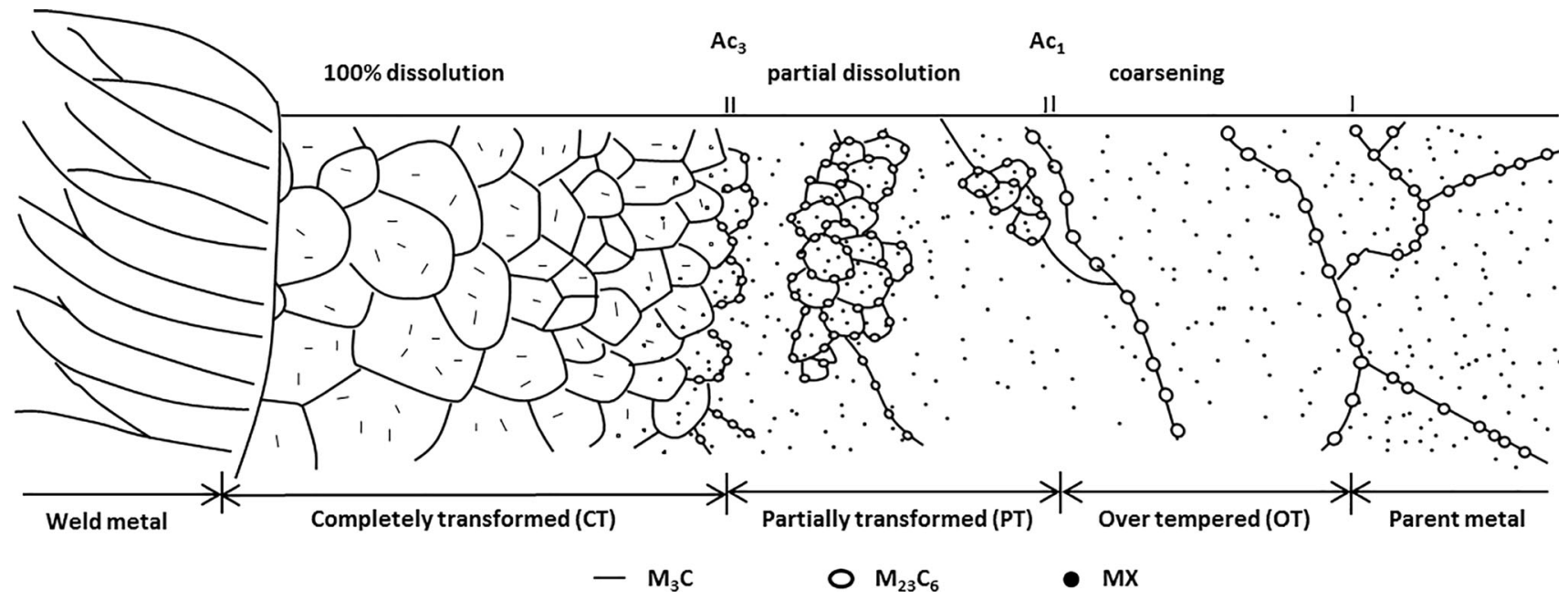

Fig. 24-Schematic diagram illustrating the classification of the HAZ microstructure in an as-welded single-pass Grade 92 weld.

$\left(1000{ }^{\circ} \mathrm{C}\right)$, a larger fraction of the MX particles were $\mathrm{Nb}$ rich compared to the simulated samples that had experienced a lower peak temperature (Figure 17), consistent with previous observations obtained by the STEM EDX mapping analyses ${ }^{[17]}$ and attributable to the higher stability of the Nb-rich compared to V-rich MX precipitates at temperatures in excess of $1273 \mathrm{~K}$ $\left(1000{ }^{\circ} \mathrm{C}\right) .{ }^{5,30]}$

It is worth noting that the conventional definitions of the HAZ microstructure, primarily in low alloy steel welds, involves a further classification of the regions with a peak temperature above the $A c_{3}$ temperature into the so-called coarse-grain and fine-grain regions, related to whether the grain structure was significantly influenced by second-phase particles. ${ }^{[1,2,14]}$ However, it was observed in this case that the rapid weld thermal cycle results in the $A c_{3}$ temperature being close to the temperature at which the pre-existing secondary precipitates are completely dissolved. Thus, although some variation in the grain structure in the regions that were heated above the $A c_{3}$ temperature was observed (Figures 20 and 21), this was primarily a function of distance from the weld line, rather than being caused by the presence of undissolved secondary precipitates. Therefore, all of the regions that were exposed to a peak temperature above the $A c_{3}$ temperature are proposed to be termed "completely transformed" (CT) regions, considering that the original microstructure in the parent metal was completely changed upon weld thermal cycles with full particle dissolution.

A reduction in hardness was observed as a function of distance from the weld line (Figure 18), through the regions showing a partially reaustenitized microstructure in the HAZ of the bead-on-plate weld, which can be attributed to a decreased fraction of the freshly formed and untempered martensite as the distance from the weld line increases. However, it should also be noted that in these regions, undissolved secondary particles after the weld thermal cycle were observed with an increase in size and number density (Figure 22), which may lead to a further decrease in hardness with distance from the weld line due to reduction in the concentration of carbon and alloying elements in the matrix offset by the strengthening effect of the precipitates. 
Using ion-beam-induced secondary electron imaging, secondary precipitates were found to be partially dissolved in the simulated samples with a peak temperature of $1173 \mathrm{~K}\left(900{ }^{\circ} \mathrm{C}\right)$, whereas upon a peak temperature of no higher than $1123 \mathrm{~K}\left(850^{\circ} \mathrm{C}\right)$, secondary precipitates were found to be coarsened after the simulated weld thermal cycle (Figure 11). The particle analysis on the carbon extraction replicas has indicated that the $\mathrm{M}_{23} \mathrm{C}_{6}$ and $\mathrm{MX}$ precipitates are both the predominant type of precipitates in the simulated samples after weld thermal cycle simulations (Table IV). However, it was observed that the MX precipitates were not significantly affected by the simulated weld thermal cycles with a peak temperature of lower than $1273 \mathrm{~K}\left(1000{ }^{\circ} \mathrm{C}\right)$ (Figure 17); therefore, the $\mathrm{M}_{23} \mathrm{C}_{6}$ carbides are considered as the main particles that are sensitive to the variation of peak temperature for thermal cycles peaking at temperatures of $\sim 1273 \mathrm{~K}\left(1000{ }^{\circ} \mathrm{C}\right)$.

Considering that the transition temperature of the dissolution and coarsening of the $\mathrm{M}_{23} \mathrm{C}_{6}$ carbides is close to the $A c_{1}$ temperature of the parent metal, the regions in the HAZ that were heated to a temperature below the $A c_{3}$ temperature can be classified into two regions: one associated with the partial reaustenitization of the original matrix and the partial dissolution of the pre-existing secondary precipitate particles with an intercritical peak temperature between the $A c_{1}$ and $A c_{3}$ temperatures; the other involved with the coarsening of the pre-existing secondary precipitate particles with a peak temperature of slightly below the $A c_{1}$ temperature.

Compared with the existing definition of the HAZ microstructure in $9 \mathrm{wt}$ pct $\mathrm{Cr}$ steel welds, ${ }^{[1,2,14]}$ the ranges of the corresponding peak temperatures of these two regions are close to the so-called intercritical and so-called overtempered (OT) regions, respectively. However, the terminology intercritical does not clearly indicate the fact that not only the martensitic matrix was partially reaustenitized but also the secondary precipitates in the original matrix were affected by weld thermal cycles. Thus, the corresponding regions in the HAZ that were exposed to an intercritical peak temperature are proposed to be termed the "partially transformed" (PT) regions. Figure 24 summarizes the classification of the HAZ microstructure in Grade 92 steel welds proposed in this research.

The PT region exhibits a substantially refined grain structure together with an incomplete dissolution of the pre-existing secondary precipitates; therefore, it is expected to be the most sensitive region for the classical Type IV failure. The refined grain structure can promote the accumulation of creep damage due to locally increased grain boundary diffusion, ${ }^{[1]}$ combined with a reduced ability of the second-phase particles to inhibit grain boundary motion.

\section{CONCLUSIONS}

A combination of the detailed analysis of a single-pass bead-on-plate weld with samples that have undergone thermal cycles to specific temperatures has shown that due to the high heating rates experienced during weld thermal cycles, transformations in the microstructure are critical in relation to the $A c_{1}$ and the $A c_{3}$ transformation temperatures of the parent metal. In particular, temperature regimes can result in the coarsening of pre-existing $\mathrm{M}_{23} \mathrm{C}_{6}$ particles or the full dissolution of precipitates depending on the peak temperature. Therefore, the HAZ of the as-welded Grade 92 single-pass weld can be categorized into the regions, as follows:

1. the CT region (i.e., $>A c_{3}$ ), in which the original matrix of the parent metal is fully reaustenitized with a complete dissolution of the pre-existing secondary precipitate particles;

2. the PT region (i.e., between $A c_{1}$ and $A c_{3}$ ), in which the original matrix is only partially reaustenitized together with a partial dissolution of the pre-existing precipitate particles; and

3. the OT region (i.e., $<A c_{1}$ ), in which the grain structure remains similar to the original matrix in the parent metal, however, the pre-existing secondary precipitate particles are coarsened during welding.

The PT region is considered to be the critical region in the HAZ that is likely to be the most susceptible to creep failure during long-term service.

\section{OPEN ACCESS}

This article is distributed under the terms of the Creative Commons Attribution 4.0 International License (http://creativecommons.org/licenses/by/4.0/), which permits unrestricted use, distribution, and reproduction in any medium, provided you give appropriate credit to the original author(s) and the source, provide a link to the Creative Commons license, and indicate if changes were made.

\section{REFERENCES}

1. R.W.K Honeycombe and H.K.D.H Bhadeshia: Steels: Microstructure and Properties, 2nd ed., Edward Arnold, London, 1995, pp. 298-306.

2. J. Gianetto, J. Braid, J. Bowker, and W. Tyson: J. Offshore Mech. Arct., 1997, vol. 119, pp. 134-44.

3. S. Mannan and K. Laha: Trans. Ind. Inst. Met., 1996, vol. 49, pp. 303-20.

4. D. Richardot, J. Vaillant, A. Arbab, and W. Bendick: The T92/ P92 Book, Dusseldorf, Vallourec and Mannesmann Tubes, 2000, pp. 17-18.

5. P. Ennis and A. Czyrska-Filemonowicz: Sadhana, 2003, vol. 28, pp. 709-30.

6. G.M. Marcello Consonni: Weld. Cutt., 2013, vol. 11, pp. 169-73.

7. J. Francis, W. Mazur, and H. Bhadeshia: Mater. Sci. Technol., 2006, vol. 22, pp. 1387-95.

8. Y. Liu, S. Tsukamoto, T. Shirane, and F. Abe: Metall. Mater. Trans. A, 2013, vol. 44A, pp. 4626-33.

9. S. Albert, M. Matsui, T. Watanabe, H. Hongo, K. Kubo, and M. Tabuchi: Int. J. Press. Vess. Pip., 2003, vol. 80, pp. 405-13.

10. T. Sakthivel, M. Vasudevan, K. Laha, P. Parameswaran, K. Chandravathi, S.P. Selvi, V. Maduraimuthu, and M. Mathew: Mater. Sci. Eng. A, 2014, vol. 591, pp. 111-20.

11. K. Shinozaki, D. Li, H. Kuroki, H. Harada, K. Ohishi, and T. Sato: Sci. Technol. Weld. Join., 2003, vol. 8, pp. 289-95.

12. D. Li, K. Shinozaki, H. Harada, and K. Ohishi: Mater. Trans. A, 2005, vol. 36, pp. 107-15. 
13. K. Chandravathi, K. Laha, K. Bhanu Sankara Rao, and S. Mannan: Mater. Sci. Technol., 2001, vol. 17, pp. 559-65.

14. K. Laha, K. Chandravathi, P. Parameswaran, K.B.S. Rao, and S. Mannan: Metall. Mater. Trans. A, 2007, vol. 38A, pp. 58-68.

15. F. Humphreys: J. Mater. Sci., 2001, vol. 36, pp. 3833-54.

16. M. Phaneuf: Micron, 1999, vol. 30, pp. 277-88.

17. K. Sawada, T. Hara, M. Tabuchi, K. Kimura, and K. Kubushiro: Mater Charact., 2015, vol. 101, pp. 106-13.

18. L. Li, P. Zhu, G. West, and R.C. Thomson: Advances in Materials Technology for Fossil Power Plants: Proc. 6th Int. Conf., ASM International, Materials Park, OH, 2011, pp. 679-92.

19. D. Abson and J. Rothwell: Int. Mater. Rev., 2015, vol. 58, pp. $437-73$.

20. C. Das, A. Bhaduri, S. Lakshmi, S. Chakravarty, S. Kar, and S. Albert: Weld. World, 2015, vol. 59, pp. 513-19.

21. P.W. Fuerschbach and G.R. Eisler: Trends in Welding Research: Proc. 6th Int. Conf., ASM International, Materials Park, OH, 2003, pp. 782-86.

22. H. Kitahara, R. Ueji, N. Tsuji, and Y. Minamino: Acta Mater., 2006, vol. 54, pp. 1279-88.
23. L. Ryde: Mater. Sci. Technol., 2006, vol. 22, pp. 1297-1306.

24. M. Yoshino, Y. Mishima, Y. Toda, H. Kushima, K. Sawada, and K. Kimura: ISIJ Int., 2005, vol. 45, pp. 107-15.

25. K. Kaneko, S. Matsumura, A. Sadakata, K. Fujita, W. Moon, S. Ozaki, N. Nishimura, and Y. Tomokiyo: Mater. Sci. Eng., 2004, vol. 374, pp. 82-89.

26. M.L. Santella: J. Press. Vess. Technol., 2012, vol. 134, pp. 1-5.

27. ASTM A1033-04: Standard Practice for Quantitative Measurement and Reporting of Hypoeutectoid Carbon and Low-Alloy Steel Phase Transformations, ASTM International, Materials Park, OH, 2004, pp. $1-14$

28. D. Deng and H. Murakawa: Comput. Mater. Sci., 2006, vol. 37, pp. 269-77.

29. R.C. Maclachlan, J.J. Sanchez-Hanton, and R.C. Thomson: $A d-$ vances in Materials Technology for Fossil Power Plants: Proc. 6th Int. Conf., ASM International, Materials Park, OH, 2011, pp. 787-99.

30. K. Suzuki, S. Kumai, Y. Toda, H. Kushima, and K. Kimura: ISIJ Int., 2003, vol. 43, pp. 1089-94.

31. M. Kassner and T. Hayes: Int. J. Plast., 2003, vol. 19, pp. 1715-48. 